\title{
ATMOSPHERIC INPUT OF TRACE METALS TO THE WESTERN MEDITERRANEAN SEA: 1. FACTORS CONTROLLING THE VARIABILITY OF ATMOSPHERIC CONCENTRATIONS
}

\author{
F. Dulac, P. Buat-Ménard, M. Amold, and U. Ezat \\ Centre des Faibles Radioactivités, Centre National de la Recherche Scientifique/ Commissariat à l'Energie Atomique \\ Gif-sur-Yvette, France \\ D. Martin
}

Etablissement d'Etudes et de Recherches Météorologiques, Magny-les-Hameaux, France

Abstract. The factors controlling the variability of atmospheric trace metal concentrations over the western Mediterranean Sea have been investigated using a combination of geochemical and meteorological approaches. $\mathrm{Al}, \mathrm{Br}, \mathrm{Cd}, \mathrm{Na}, \mathrm{Pb}$ and $210 \mathrm{Po}$ concentrations from bulk filters and cascade impactor samples collected during five cruises (1980-1983) have been used to characterize the aerosol sources: the marine source $(\mathrm{Na})$, the aeolian soil mobilization $(\mathrm{Al})$, the anthropic sources $(\mathrm{Cd}, \mathrm{Pb})$, and the volcanic source $(210 \mathrm{Po})$. It has been confirmed that $\mathrm{Cd}$ and $\mathrm{Pb}$ directly derive from anthropic sources. As shown by three-dimensional air mass trajectory analyses, the variability of daily atmospheric concentrations reflects both changes in continental source strengths and in airflow patterns. Atmospheric concentrations appear to be higher during episodes of short-range transport of continental material from riparian countries. It is suggested that such source regions can be precisely identified by a careful examination of both geochemical data and three-dimensional trajectories. From our data set, southwestern Europe would be responsible for the largest $\mathrm{Pb}$ and $\mathrm{Cd}$ inputs to the western Mediterranean atmosphere (30-40\%), but the inputs from North Africa are also likely to be significant (20-25\%). However, it cannot be ascertained whether this conclusion is valid on a yearly time scale. Indeed, whereas our sample set is representative of the yearly airflow climatology, it has not been possible to assess the effect of seasonal (for $\mathrm{Pb}$ ) or sporadic (for Al) changes in source strengths. This points out that over such a marine environment, continuous sampling programs are needed to assess the respective contributions of individual source regions to the atmospheric burden of particulate trace elements.

\section{Introduction}

On the basis of previous analyses of aerosol samples throughout the western Mediterranean, it has been observed that atmospheric trace metal concentrations are generally high compared to those found over remote marine environments and are highly variable on a daily time scale [Arnold et al., 1982; Chester et al., 1984; Arnold, 1985]. Moreover, it has been suggested that a substantial fraction of metallic input entering this sea derives from industrial sources via atmospheric transport [Amold, 1985]. Such a transport could cause $10-20 \%$ of the European anthropic emissions of particulate $\mathrm{Cd}, \mathrm{Cu}, \mathrm{Zn}$, and $\mathrm{Pb}$ in the atmosphere to enter the waters of this basin. However, quantitative assessment of this input is difficult because of the strong variability of atmospheric elemental concentrations. This variability can be due to changes in both source strengths and airflow patterns. Our present objective is to show that the combined use of geochemical informations and air mass trajectories supports this hypothesis and that such an approach can lead to a quantitative assessment of the different sources and source regions for the atmospheric pollution over a regional sea. In a subsequent paper we will focus on the removal of aerosol particles by wet and dry deposition to the sea surface.

This work is based on measurements of $\mathrm{Al}, \mathrm{Na}, \mathrm{Br}, \mathrm{Pb}, \mathrm{Cd}$, and ${ }^{210} \mathrm{Po}$ concentrations in the western Mediterranean aerosol. These elements have been chosen because of their potential use as geochemical tracers. Among the main sources for inorganic particles in the

Copyright 1987 by the American Geophysical Union.

Paper number 7D0186.

0148-0227/87/007D-0186\$05.00 troposphere [Hidy, 1984], three natural sources have been clearly evidenced in the western Mediterranean [Amold, 1985]: the marine source producing sea-salt particles by bubble bursting at the sea surface [Blanchard, 1983]; the continental aeolian source, resulting from the soil dust mobilization by wind [Morales, 1979]; and the volcanic emissions from the two active volcanoes Mount Etna and Stromboli [Buat-Ménard and Arnold, 1978]. Another important source for atmospheric particulate metals in the basin is the anthropic activity [Arnold, 1985]. As commonly used in litterature, $\mathrm{Na}$ and $\mathrm{Al}$ were considered as the respective reference elements for aerosols derived from the sea surface and from the dispersion of soil material. Nearly $90 \%$ of the global Cd atmospheric emissions and $97 \%$ of the $\mathrm{Pb}$ emissions [Nriagu, 1979] derive from human activities, and these two elements have been considered as tracers for anthropic pollution. Of the European $\mathrm{Pb}$ emissions, 60\% derive from vehicle exhaust [Pacyna, 1984] due to gasoline alkyl-lead additives. Such products contain $\mathrm{Pb}$ mixed $(\mathrm{Br}-\mathrm{Cl})$ halides, so that a correlation can be found between $\mathrm{Br}$ and $\mathrm{Pb}$ concentrations in the Mediterraneean aerosol [Amold, 1985], although $\mathrm{Br}$ is also produced by the marine source [Kritz and Rancher, 1980]. Volcanoes are the main source for ${ }^{210} \mathrm{Po}$, and it has been shown that the excess of $210 \mathrm{Po}$ over $210 \mathrm{~Pb}(210 \mathrm{Po} / 210 \mathrm{~Pb}$ activity ratio $>0.25)$ unequivocally results from the presence of submicrometer volcanic aerosols [Lambert et al., 1982a, b].

\section{Materials and Methods}

\section{Sampling}

Atmospheric samples were collected from a bow tower extending forward of the ship (R/V Le Noroit, R/V Le Suroitt, or R/V Le Cornide de Savedra) $8 \mathrm{~m}$ above sea level, using wind direction control to avoid contamination from the ship. Acid washed Whatman ${ }^{\otimes} 41$ filters were used for collection. Sample change on board was performed inside a dust-free laminar flow bench using ultra-clean procedures. Blank filters were subjected to all the manipulations made on the filters, except air filtration. These sampling techniques have been previously described by Buat-Ménard and Chesselet [1979], Seghaier [1984], and Arnold [1985]. Seventy-two bulk aerosol samples (double filter; diameter, $7.5 \mathrm{~cm}$; airflow, $8.5 \mathrm{~m}^{3} \mathrm{~h}^{-1}$ ) have been collected on a daily time scale during five cruises throughout the western Mediterranean: (1) ETNA 80 (September 1980]; (2) PHYCEMED 81 (April 1981); (3) ALBORAN 81 (October 1981); (4) ETNA 82 (December 1982); and (5) PHYCEMED 83 (October 1983). Sampling locations during these five cruise tracks are shown in Figures 1,2, and 3. Details of the sampling locations and conditions have been published elsewhere [Amold, 1985; Dulac, 1986)].

A Sierra ${ }^{\circledR} 235$ slotted cascade impactor has been used to collect 18 additional 1 to 5-day, size-separated aerosol samples. This impactor is a five-stage high-volume sampler. At the operational flow rate of $68 \mathrm{~m}^{3}$ $\mathbf{h}^{-1}$, the cutoff diameters experimentally determined for solid spheres of methylene blue are as follows from the stage 1 to $5: 7.2 ; 3 ; 1.5 ; 0.95$ and $0.49 \mu \mathrm{m}$ [Knuth, 1979]. A backup filter collects the smallest particles. The cutoff diameter can be considered as the lower limit size for particle collection on the given stage, although the separation is not perfect. There is also evidence that the experimental mass-size distributions of aerosol particles are shifted towards small particles, as a result of bounce effects [Walsh et al., 1978; Buat-Ménard et al., 1983]. However, the total elemental concentrations from the two sampling 


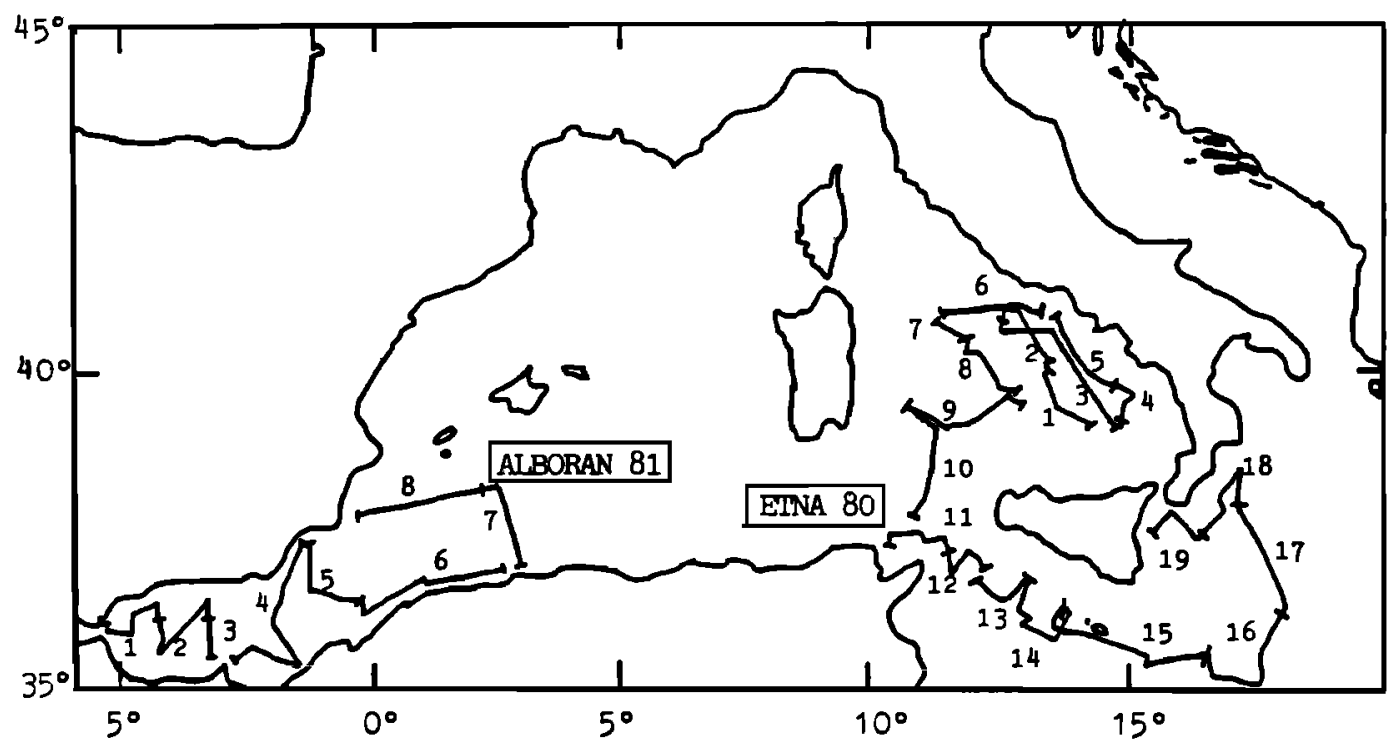

Fig. 1. Sampling locations during the ETNA 80 and ALBORAN 81 cruises.

systems, bulk filtration and cascade impaction, were found to be statistically comparable [Dulac, 1986].

\section{Analytical Methods}

Direct $a$ and $b$ counting of ${ }^{210} \mathrm{~Pb}$ and $210 \mathrm{Po}$ activities [Polian and Lambert, 1979] have been performed on filters from the ETNA 80 and 82, and PHYCEMED 83 cruises. Flameless atomic absorption spectroscopy and instrumental neutron activation analyses ("long" or "short" procedure) were performed on aliquots of the filters. Intercalibrations have been made to allow the full comparison of results from these three analytical procedures [Seghaier, 1984; Dulac, 1986].

Aliquots of most bulk filters and some impactor filters have been analyzed by flameless atomic absorption spectroscopy for $\mathrm{Al}, \mathrm{Pb}$ and $\mathrm{Cd}$, after a $\mathrm{HNO}_{3}-\mathrm{HCl}$ dissolution procedure [Seghaier, 1984; Ezat, 1986]. A Perkin Elmer model 2380 spectrometer equipped with a graphite furnace model 400 was used. A European standard reference material (876-1/ Electric Furnace Dust from the European Coal and Steel Community, 1977) was used to verify the calibration by elemental standards.
An aliquot of each bulk filter from the first three cruises has been analyzed by "long" neutron activation and counting for $\mathrm{Br}$ and $\mathrm{Na}$, while an aliquot of each bulk and impactor sample from PHYCEMED 83 has been analyzed by "short" neutron activation analysis for $\mathrm{Al}, \mathrm{Br}$ and $\mathrm{Na}$, using the irradiation and counting facilities provided by the Laboratoire Pierre Süe, Centre d'Etudes Nucléaires at Saclay, France. The filter aliquots were pelletized in a Plexiglas liner, using a hand press (pellet size: $10 \mathrm{~mm}$ in diameter, $4-6 \mathrm{~mm}$ in thickness). The long procedure consisted of irradiation in a thermal neutron flux of $10^{14} \mathrm{n} \mathrm{cm}^{-2} \mathrm{~s}^{-1}$ for 1 hour in the $70 \mathrm{MW}$ research reactor OSIRIS of the Centre d'Etudes Nucleaires. The samples were cooled for about 4 days and counted for 1-3 hours on a $110 \mathrm{~cm}^{3} \mathrm{Ge}(\mathrm{Li})$ detector. The short procedure consisted of irradiation in a thermal neutron flux of $2.45 \times 10^{13} \mathrm{n} \mathrm{cm}^{-2} \mathrm{~s}^{-1}$ for $1-4$ $\mathrm{mn}$ in the $14 \mathrm{MW}$ research reactor ORPHEE at Saclay. The samples were counted for 300-600 s after 2 to12-mn cooling, on a $50 \mathrm{~cm}^{3} \mathrm{Ge}(\mathrm{Li})$ detector, and were analyzed using an automated method [Delmas et al. 1987]. The single-comparator method was used throughout the neutron activation analyses [Girardi et al., 1965]. Multielemental calibration was made with elemental standards, and verified with international standard

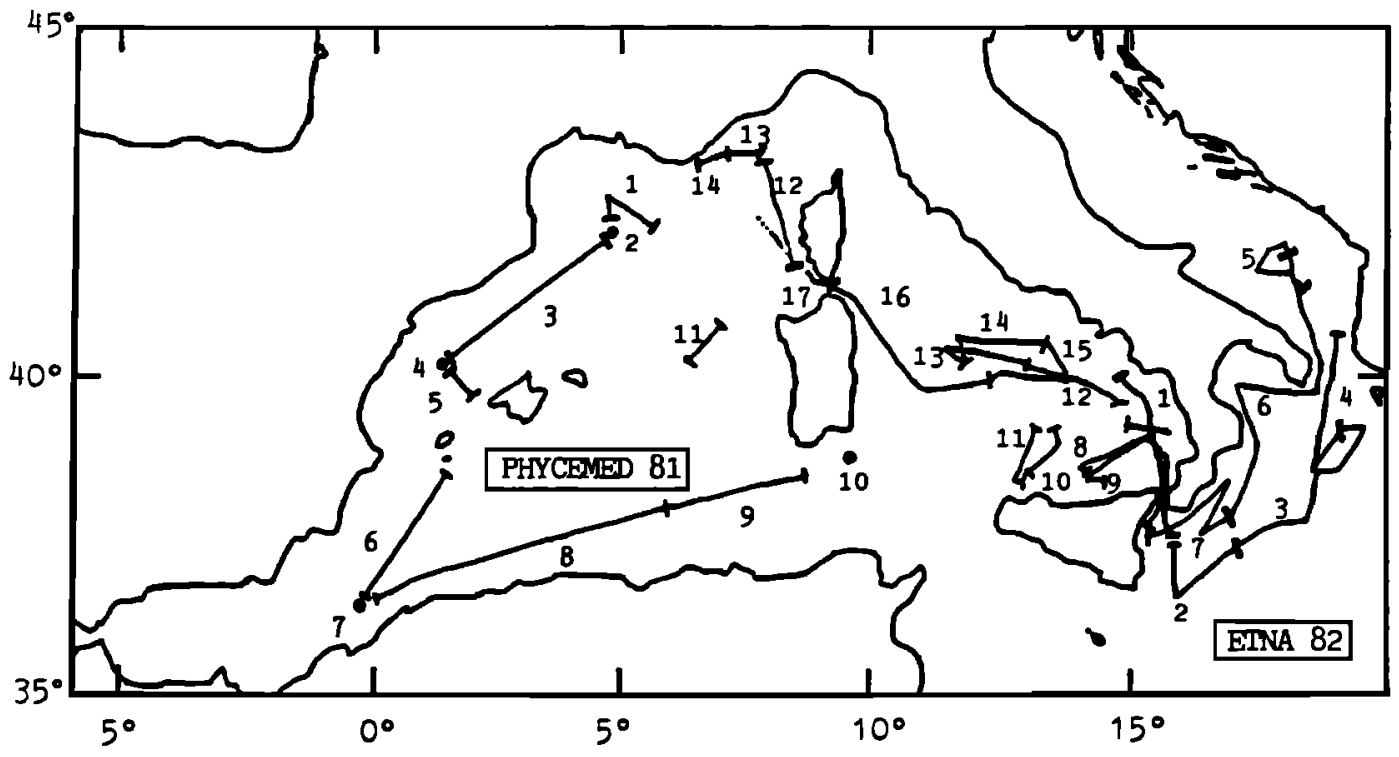

Fig. 2. Sampling locations during the PHYCEMED 81 and ETNA 82 cruises. 


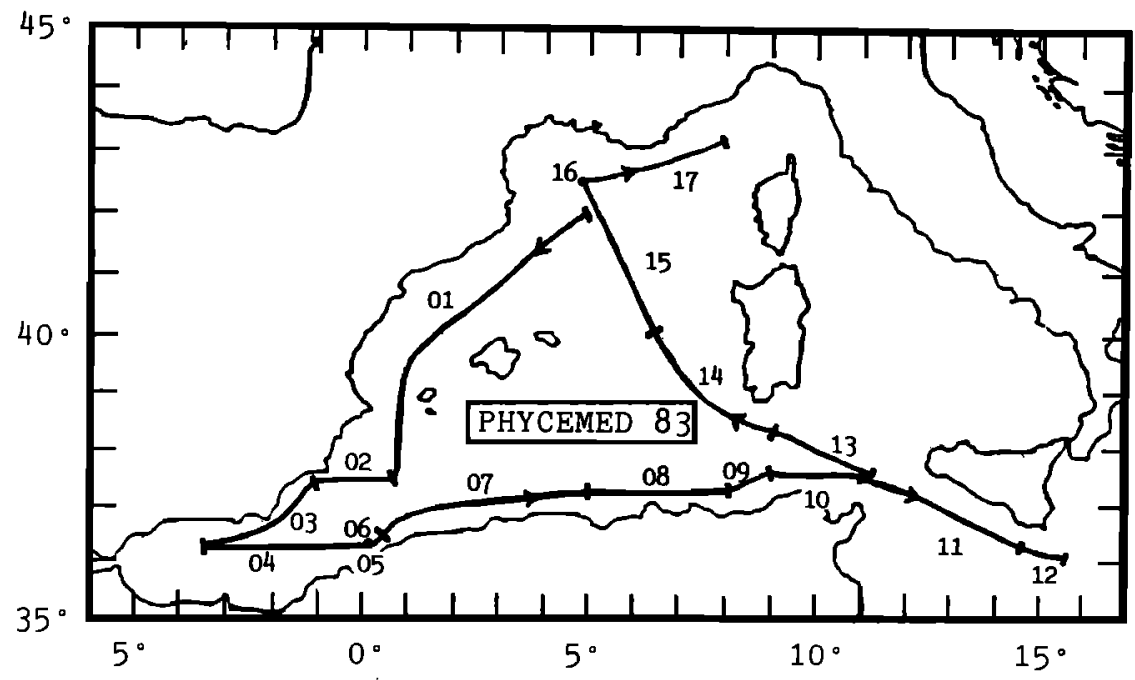

Fig. 3. Sampling locations during the PHYCEMED 83 cruise.

reference materials (USGS W-1/Diabase from the U.S Geological Survey; SRM 1632/Trace Elements in Coal, and SRM 1633/Trace Elements in Coal Fly Ash, from the National Bureau of Standards) [Dulac, 1986; Delmas et al., 1987].

Results have been corrected for blanks on the basis of analyses of precleaned blank filters handled on the ship. Several filters from each set were analyzed so that we could take into account the variability of blank values to calculate relative errors on the final results [Dulac, 1986]. Mean relative errors have been estimated to be $10 \%$ for $\mathrm{Cd}$ and $12 \%$ for $\mathrm{Pb}$ analyses [Seghaier, 1984]. The mean statistical errors for neutron activation analyses, expressed as $2 \mathrm{~s}$, calculated according to the standard relation of Currie [1968], and taking into account blank errors, are generally less than $10 \%$ for $\mathrm{Al}$ and $\mathrm{Na}$ analyses and about $30 \%$ for $\mathrm{Br}$ analyses.

\section{Air Mass Traiectories}

The transport of aerosol particles is highly dependent on the mean motion of the air parcel in which they are suspended, as their deposition velocity is generally low compared to the horizontal velocity of the air. In order to assess the transport of aerosol particles from their source regions, air mass trajectories have been computed during the sampling periods by the Service des Etudes Spéciales, Météorologie Nationale, Paris. Four-day back trajectories finishing at the midpoint of each sampling time have been computed using two different models. For the ETNA cruises, trajectories are based on winds calculated from the geopotential fields using the geostrophic approximation (Isobaric model: Sykes and Hatton [1976]; Martin et al. [1984]). Two trajectories were computed at the $850-$ and $700-\mathrm{hPa}$ levels. For the other samples, trajectories are three-dimensional, arriving at the $925-\mathrm{hPa}$ final level, and computed from the analyzed wind fields of the European Center for Medium-Range Weather Forecasts of Reading, England [Lorenc et al., 1977]. Comparisons between the two types of models [Martin et al. 1987] or between isentropic and isobaric models [Artz et al., 1985] have shown a good agreement, except for frontal or high-pressure situations for which large vertical air motions cause misleading results for constant-level trajectories. Also, uncertainties occur for both constantand variable-level trajectories during periods of precipitation. Such errors are due to important vertical motions of the air on a scale too small for the meteorological observation grid. Most of these trajectories have been published by Arnold [1985] and Dulac [1986].

In order to distinguish between the main source regions, trajectories

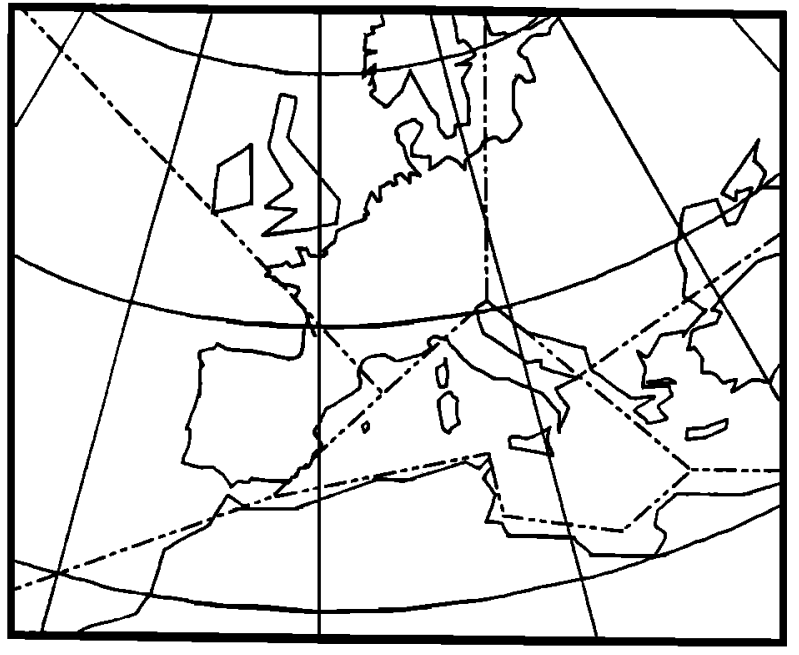

a.

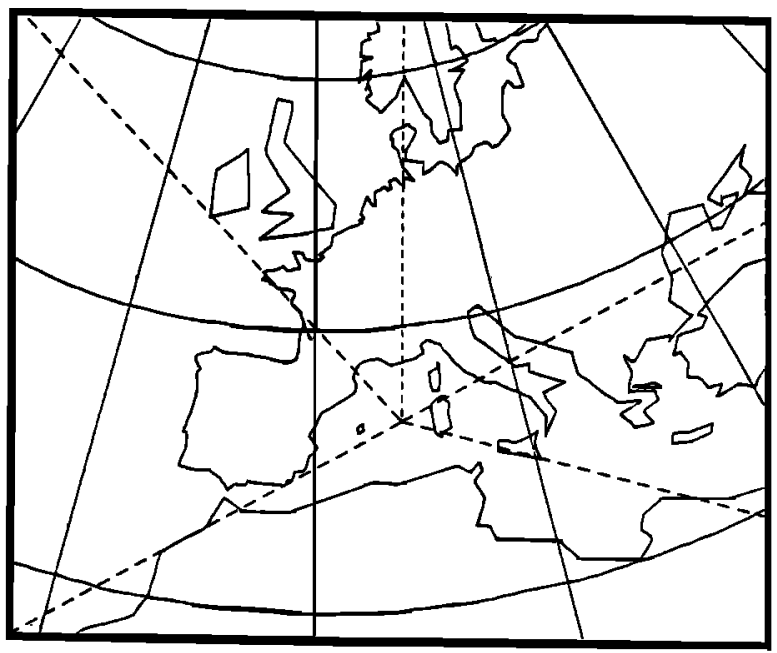

b.

Fig. 4. Sector partitioning for the geographical classification of air mass trajectories. (a) This work, six sectors (south, west, northwest, northeast, east and Mediterranean sea); (b) GESAMP (1985): Miller's four sectors with the miscellaneous or cyclonic class reported in figure 8a missing (south, west, north, east), and Martin and Strauss's five sectors (south, west, northwest, northeast and east). 


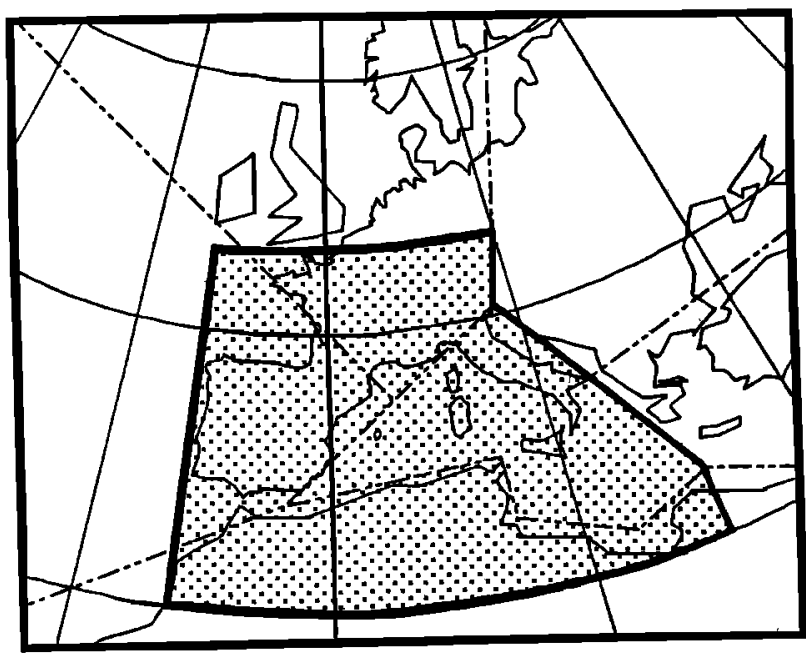

Fig. 5. Limits for separation between short trajectories (dotted area) and long trajectories for a four-day transport.

have been partitioned into geographical sectors. Such an approach, first developed by the National Oceanic and Atmospheric Administration (NOAA) Air Resources Laboratory, has been widely used to get airflow climatologies for many places in the world, in order to study long-range transport of aerosol and acidity [Miller et al.,1978; Miller, 1981a, b; Henderson and Weingartner, 1982; Martin et al., 1984; Dayan et al., 1985; Miller and Harris, 1985]. Two such airflow climatologies have been determined for the center of the western Mediterranean basin over a period of 9 years (January 1975 to December 1983) [Joint Group of Experts on Scientific Aspects of Marine Pollution (GESAMP), 1985]. They show that year-to-year variations of airflow patterns are as large as seasonal variations.

We have considered a close sector partitioning (Figure 4) to classify each of our samples according to the corresponding airflow direction. This six-sector partitioning allows us to distinguish between the main emission areas: (1) Atlantic, Iberian Peninsula and Southwestern France (west sector); (2) Western Europe (northwest); (3) Eastern Europe (northeast); (4) Africa (south); (5) Italy and the sea surface (local Mediterranean); and (6) Greece and the Middle-East (east). Moreover, we have made an additional, crude classification to separate the trajectories into long and short ones in order to evaluate the influence of riparian countries: short trajectories can be assumed to disclose aerosol transport only from nearby countries, and long trajectories can be assumed to disclose transport from both faraway and close source regions. Four-day back trajectories were associated with close source regions, when limited to the dotted area in Figure 5. Changes in airflow patterns are generally smooth enough so that evolutions may be assessed between successive trajectories, and a single trajectory at the midtime of each sampling period is sufficient to classify the samples.

\section{Results}

\section{Atmosoheric Concentrations}

Variations of $\mathrm{Al}, \mathrm{Na}, \mathrm{Br}, \mathrm{Pb}$, and $\mathrm{Cd}$ bulk concentrations are presented in Figure 6. Bulk results have been published by Dulac [1986]. The results disclose a great variability of elemental conicentrations on the daily sampling time scale, as concentrations may change by a factor of 10-20 between two successive samples. The sample PHYCEMED 81/13 shows very anomalous $\mathrm{Br}$ and $\mathrm{Na}$ concentrations and sea spray contamination must be suspected. These concentrations have been discarded from the statistics summarized in Table 1 . It can be seen that each cruise exhibits specific patterns: (1) ETNA 80, lowest Al concentrations; (2) PHYCEMED 81, strong variability for all elements and high $\mathrm{Br}$ and Na concentrations; (3) ALBORAN 81, low $\mathrm{Br}$ and $\mathrm{Na}$ concentrations, low $\mathrm{Cd}$ and $\mathrm{Pb}$ concentrations (the high-Cd arithmetic mean is due to a single high value), and high Al concentrations; (4) ETNA 82, lowest $\mathrm{Cd}$ and $\mathrm{Pb}$ concentrations; and PHYCEMED 83, mean values close to the mean values observed for the five cruises. Depending on the element, there are variations by a factor of $2-4$ between the average concentration from one cruise to another. The probability that differences occur between the set of samples from the different cruises has been calculated using an analysis of variance (AOV) and the $\mathrm{C2}$ probability function [Van der Waerden, 1967]. Despite the great variability of all elemental concentrations during each cruise, differences are significant at the $99.99 \%$ level for $\mathrm{Al}, \mathrm{Cd}$, and $\mathrm{Pb}$. This probability is lower for $\mathrm{Na}$ and $\mathrm{Br}$ (about 79\%). Indeed, Table 2 shows that each cruise occurred under quite different airflow conditions.

The mean mass-size elemental distributions are presented in Figure 7 for the PHYCEMED 83 sampling cruise. Results show that the concentration of each element is subject to variations of at least 1 order of magnitude from the less loaded to the more loaded size class. Although variations of more than 1 order of magnitude can be found between the elemental concentrations from one sample to another, the mean mass-size elemental distribution profiles were found to be conservative [Dulac, 1986]. This indicates that the high variability observed for the total concentrations similarly affects the whole size distribution spectrum.

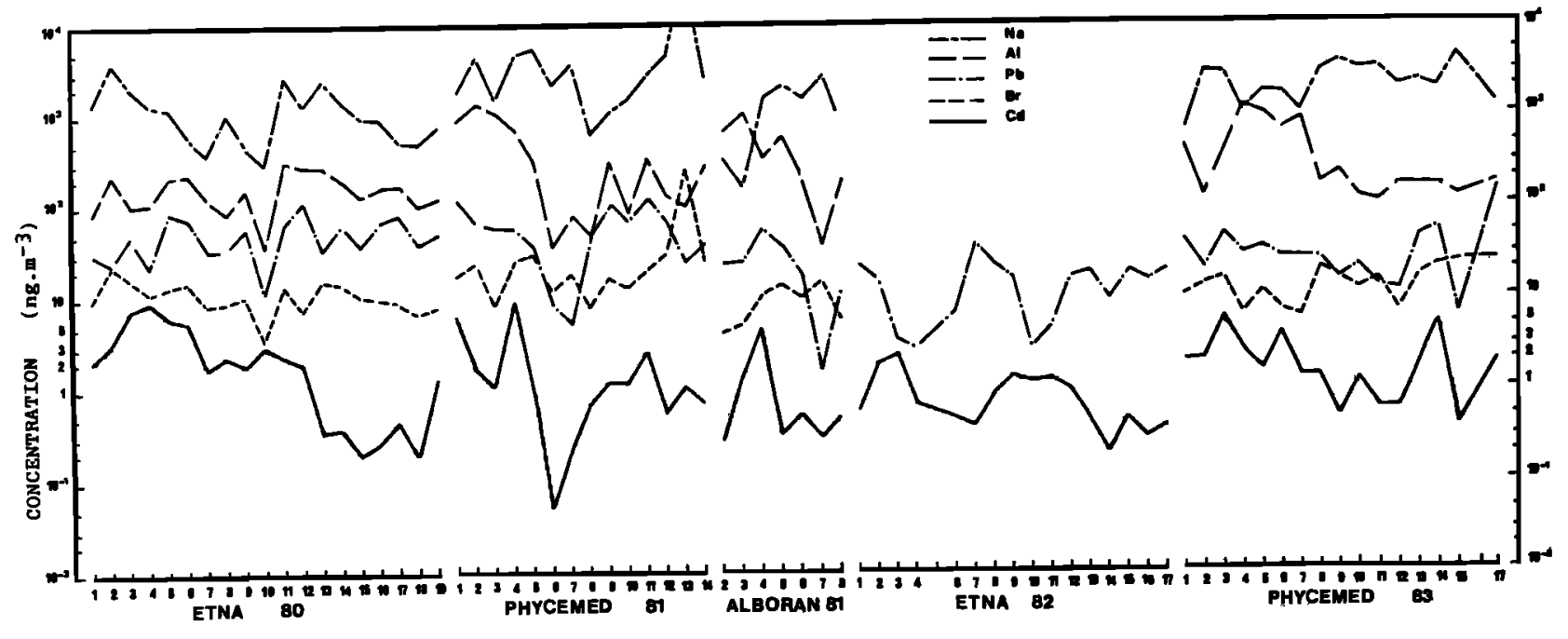

Fig. 6. Atmospheric concentrations (in nanograms per cubic meters) of $\mathrm{Na}, \mathrm{Al}, \mathrm{Pb}, \mathrm{Br}$, and $\mathrm{Cd}$, in the western Mediterranean observed during five cruises (1980-1983) (X-axis: reference number of samples). 
TABLE 1. Summary Statistics of Atmospheric Concentrations in the Western Mediterranean

\begin{tabular}{|c|c|c|c|c|c|c|c|}
\hline \multirow[t]{2}{*}{ Element } & \multirow[t]{2}{*}{ Cruise } & \multirow{2}{*}{$\begin{array}{l}\text { No. of } \\
\text { Samples }\end{array}$} & \multicolumn{2}{|c|}{ Concentration, ng $\mathrm{m}^{-3}$} & \multirow[t]{2}{*}{ Median } & \multirow[t]{2}{*}{ Arithmetic Mean } & \multirow[t]{2}{*}{ Geometric Mean } \\
\hline & & & Min. & Max. & & & \\
\hline \multirow[t]{5}{*}{ Al } & ETNA 80 & 19 & 37 & 331 & 160 & $168(79)$ & $150(1.70)$ \\
\hline & PHYCEMED 81 & 14 & 36 & 1355 & 297 & $409(423)$ & $232(3.23)$ \\
\hline & ALBORAN 81 & 7 & 38 & 1085 & 331 & $447(362)$ & $300(3.04)$ \\
\hline & PHYCEMED 83 & 16 & 103 & 1205 & 168 & $380(360)$ & $264(2.33)$ \\
\hline & ALL & 56 & 36 & 1355 & 184 & $324(327)$ & $214(2.47)$ \\
\hline \multirow[t]{5}{*}{$\mathrm{Br}$} & ETNA 80 & 19 & 3.6 & 23.2 & 10.8 & $11.6(4.5)$ & $10.8(1.51)$ \\
\hline & PHYCEMED 81 & 13 & 8.0 & 29.9 & 18.7 & $19.1(7.5)$ & $17.6(1.57)$ \\
\hline & ALBORAN 81 & 7 & 4.2 & 15.4 & 10.0 & $9.4(4.4)$ & $8.5(1.66)$ \\
\hline & PHYCEMED 83 & 16 & 6.0 & 24.4 & 14.5 & $14.0(6.0)$ & $12.8(1.59)$ \\
\hline & ALL & 55 & 3.6 & 29.9 & 12.9 & $13.8(6.5)$ & $12.3(1.64)$ \\
\hline \multirow[t]{6}{*}{$\mathrm{Cd}$} & ETNA 80 & 19 & 0.19 & 9.40 & 1.93 & $2.69(2.69)$ & $1.48(3.50)$ \\
\hline & PHYCEMED 81 & 14 & 0.05 & 9.33 & 1.09 & $2.02(2.65)$ & $1.04(3.63)$ \\
\hline & ALBORAN 81 & 7 & 0.28 & 5.07 & 0.51 & $1.21(1.75)$ & $0.66(2.87)$ \\
\hline & ETNA 82 & 16 & 0.20 & 2.40 & 0.65 & $0.89(0.62)$ & $0.71(1.99)$ \\
\hline & PHYCEMED 83 & 16 & 0.38 & 6.20 & 1.69 & $2.10(1.70)$ & $1.56(2.27)$ \\
\hline & ALL & 72 & 0.05 & 9.40 & 1.21 & $1.88(2.13)$ & $1.10(2.93)$ \\
\hline \multirow[t]{5}{*}{$\mathrm{Na}$} & ETNA 80 & 19 & 294 & 3937 & 1105 & $1300(956)$ & $1030(2.03)$ \\
\hline & PHYCEMED 81 & 13 & 624 & 5466 & 2605 & $2855(1575)$ & $2405(1.92)$ \\
\hline & ALBORAN 81 & 7 & 157 & 2839 & 1510 & $1340(981)$ & $930(2.88)$ \\
\hline & PHYCEMED 83 & 16 & 693 & 3701 & 2085 & $2275(1045)$ & $2030(1.68)$ \\
\hline & ALL & 55 & 157 & 5466 & 1600 & $1955(1300)$ & $1515(2.20)$ \\
\hline \multirow[t]{6}{*}{$\mathrm{Pb}$} & ETNA 80 & 19 & 11.5 & 118.1 & 48.3 & $51.8(26.6)$ & $45.2(1.75)$ \\
\hline & PHYCEMED 81 & 14 & 5.4 & 129.5 & 58.2 & $60.5(38.7)$ & $45.3(2.52)$ \\
\hline & ALBORAN 81 & 7 & 1.6 & 56.5 & 23.7 & $25.0(17.8)$ & $17.2(3.17)$ \\
\hline & ETNA 82 & 16 & 2.8 & 38.8 & 15.8 & $14.8(9.6)$ & $11.4(2.27)$ \\
\hline & PHYCEMED 83 & 16 & 6.2 & 144.0 & 26.5 & $34.9(32.2)$ & $26.7(2.09)$ \\
\hline & ALL & 72 & 1.6 & 144.0 & 30.0 & $38.9(31.8)$ & $27.0(2.60)$ \\
\hline
\end{tabular}

Numbers in parentheses indicate standard deviation; Min. Indicates minimum; Max., maximum.

\section{Airflow Patterns}

Figure 8 presents the results of our classification, together with the results of the two airflow climatologies. These climatologies give very close results [GESAMP, 1985]. Over 74 trajectories, six from ETNA 80 have not been classified because of large differences between the constant 850- and 700-hPa level trajectories. Four were classified from two sectors, with a weight of 0.5 for the frequency calculation. Our sampling seems to overestimate the west source region to the detriment of the northwest one. However, $15 \%$ of our trajectories exhibit air transport along the limit between these two sectors, and our subjective visual choice can easily explain this shift. Thus the resulting similarity allows us to consider that our data set is representative of the different airflow patterns for the western Mediterranean atmosphere. Moreover, a good agreement of meteorological situations during sampling with statistical climatologies [Reiter, 1975] has also been found [Dulac, 1986].

Figure 9 exhibits the mean atmospheric concentrations according to the sector of air mass trajectories, and Table 3 exhibits the mean concentrations resulting from the short- and long-trajectory classification. The probability that differences exist between sectors (East excepted) has been calculated by AOV. Temporal changes in source strengths could be a source of variance in the data. Although not yet documented, seasonal changes should be significant in the case of $\mathrm{Pb}$, as road traffic is likely to be drastically more intense on coastal areas during summer holidays. However, no sampling was carried out in May, June, July, and August, so that this seasonal change is not taken into account.
This may indeed affect the representativity of the $\mathrm{Pb}$ data on a yearly time scale.

\section{Discussion}

\section{Validity of the Tracers}

The basic approach for source identification is to consider the two major acrosol sources in terms of mass (the ocean and the earth's surface) and to characterize these with reference elements (Na and $\mathrm{Al}$ respectively) in order to calculate elemental enrichments in the aerosol particles, using bulk seawater or the earth's crust composition as a normalizing factor, according to the previously published formula [Rahn, 1976] (see also Table 4).

$\mathrm{Na}$. Al: Marine and crustal source. It can be seen from Table 4 that $\mathrm{Na}$ enrichments relative to crust or soil composition are not high: respective geometric means are about 27 and 9 . Indeed, the Na/Al reference value for soil is only 0.89 [Vinogradov, 1959; Bowen, 1966], and the validity of $\mathrm{Na}$ as a tracer for sea-salt particles may be questionable [Arimoto et al., 1985]. Considering that $\mathrm{Al}$ is a perfect tracer for crust-derived (natural or anthropic) aerosol and the mean crustal ratio of 0.29 for the $\mathrm{Na} / \mathrm{Al}$ ratio (see Table 4), we have corrected the $\mathrm{Na}$ concentration for a crustal contribution. The supposed marine $\mathrm{Na}$ concentrations $\left(\mathrm{Na}_{\mathrm{m}}\right)$ were calculated by the following formula:

$$
\mathrm{Na}_{m}=\mathrm{Na}-0.29 \times \mathrm{Al}
$$


TABLE 2. Geographical Classification of Trajectories During Sampling

\begin{tabular}{lcccccc}
\hline \multirow{2}{*}{ Cruise } & \multicolumn{5}{c}{ Frequencies of Air Mass Origin, \% } \\
& West & Northwest & Northeast & East & South & Local \\
\cline { 2 - 7 } & 50 & 4 & 19 & 0 & 0 & 27 \\
\hline ETNA 80 & 18 & 43 & 0 & 0 & 32 & 7 \\
PHYCEMED 81 & 57 & 0 & 0 & 0 & 43 & 0 \\
ALBORAN 81 & 59 & 6 & 18 & 6 & 6 & 6 \\
PHNA 82 & 50 & 6 & 18 & 0 & 0 & 26 \\
All Cruises & 46.3 & 12.5 & 12.5 & 1.5 & 12.5 & 14.7 \\
\hline
\end{tabular}

Although the calculated crustal influence is generally negligible, corresponding to a Na/Al ratio higher than 6 , it becomes more than $10 \%$ when the $\mathrm{Na} / \mathrm{Al}$ ratio is lower than 3 and reaches more than $20 \%$ for a few samples. Therefore this emphasizes that $\mathrm{Na}$ should be carefully used as a tracer of sea-salt particles, in particular when considering continental or urban aerosols. As a consequence of mechanical emission processes, $\mathrm{Na}$ and $\mathrm{Al}$ are mainly found in particles more than $3 \mu \mathrm{m}$ in diameter

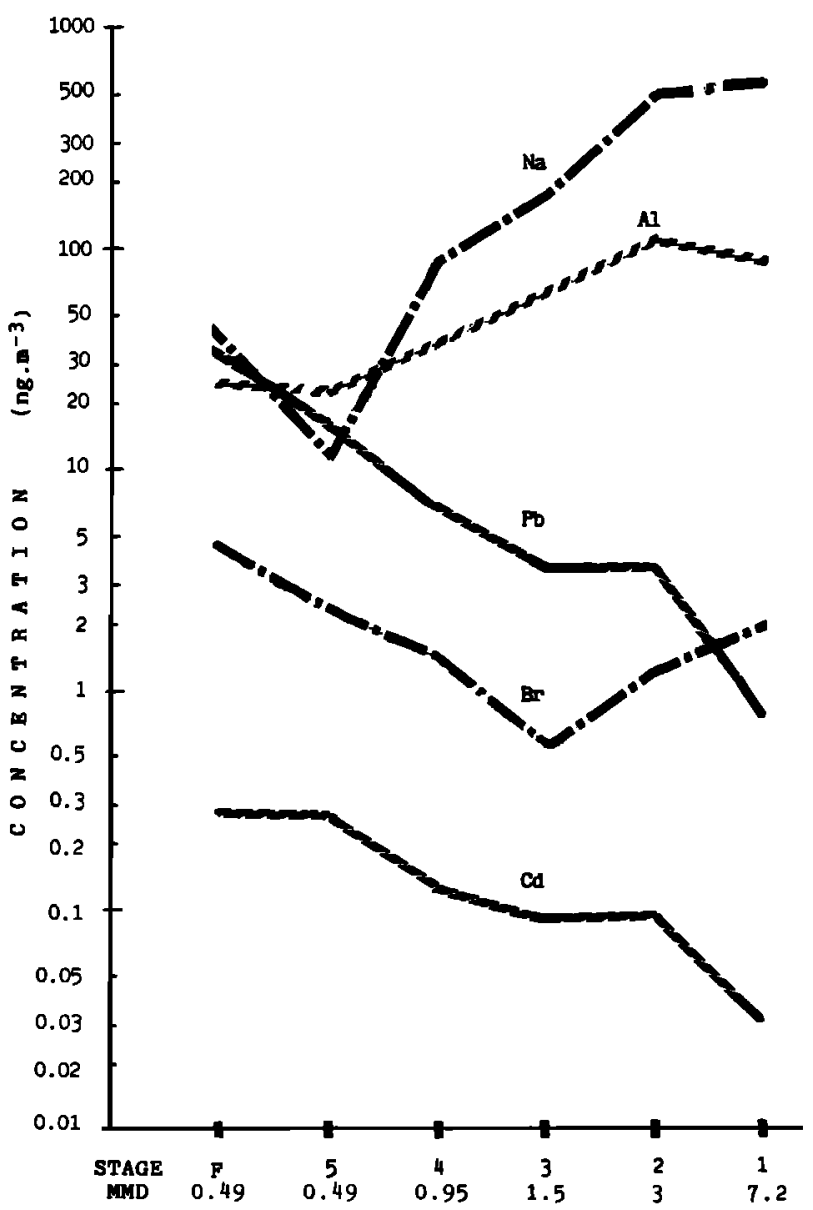

Fig. 7. Mean mass-size distributions during PHYCEMED 83 cruise (eight impactor samples, except for $\mathrm{Pb}$ and $\mathrm{Cd}$ : samples I 3-4-5 and I 17).
[Duce et al., 1976b; Rahn, 1976], 80 and $60 \%$ of their total mass respectively, on the first two impactor stages (Figure 7).

$\mathrm{Cd}$. Pb: Anthropic sources. The mean enrichment factors presented in Table 4 show that $\mathrm{Cd}$ and $\mathrm{Pb}$ are present in the atmosphere at much higher concentrations (at least 140 times more) than can be accounted for by the simple dispersion of soil or seawater. The long-range transport of anthropic aerosol has been recognized as the source for these enriched elements in remote marine aerosols. Their emissions occur in the vapor phase by high-temperature combustion processes and are followed by condensation [Rahn, 1976]. As a consequence, these enriched elements occur preferentially in the submicrometer fraction of the aerosol: $60-80 \%$ on the stage 5 and final filter (Figure 7).

However, emissions from active volcanoes also occur in the vapor phase at high temperature, and the Mount Etna volcano, among others, has been recognized as a source for tropospheric heavy metals [Buat-Ménard and Amold, 1978]. As a direct assessment of volcanic versus pollution sources is not possible from source strengths, we used the geochemical tracer $210 \mathrm{Po} / 210 \mathrm{~Pb}$ to assess the presence of volcanic aerosols in our samples. Among the 51 bulk aerosol samples from ETNA 80 and 82 and PHYCEMED 83, only seven samples exhibited excess ${ }^{210} \mathrm{Po}$. Using the ratios of heavy metal/210 Po concentrations observed in the Mount Etna plume, it appears that the volcanic influence is less than a few percent of the heavy metal concentrations for these samples [Arnold et al., 1982; Arnold, 1985]. Therefore we consider that volcanic inputs of trace metals to the western Mediterranean atmosphere are negligible. It must be noticed that owing to the westerly airflow, the situation could be somewhat different over the eastem Mediterranean.

It is also known that enrichments of heavy metals in the organic surface microlayer of the sea [Piotrowicz et al., 1972] lead to high enrichments $(1,000-10,000)$ of these elements in sea-salt particles [Weisel et al., 1984]. Approximately $15 \%$ of the total particulate $\mathrm{Pb}$ measured at Enewetak Atoll would be due to this recycling, although this $\mathrm{Pb}$ has a primary anthropic source [Settle and Patterson, 1982]. Enrichment factors relative to seawater $\left(\mathrm{EF}_{\mathrm{sw}}\right)$ have been calculated using the Mediterranean surface water composition (Table 4). Values of $\mathrm{EF}_{\mathbf{s w}}$ are so high $\left(10^{5}-10^{7}\right)$ that recycling of heavy metals must be negligible in the western Mediterranean aerosol. This is even the case for the concentrations observed in the largest-particle fraction of the aerosol. Enrichment factors of $\mathrm{Pb}$ and $\mathrm{Cd}$ have been calculated for the several size classes given by impactor samples and for two samples showing either low or high $\mathrm{Pb}$ or $\mathrm{Cd}$ concentration. The results, presented in Table 5 , show that enrichments are variable with the size class of particles. They exhibit a maximum value for the fine particles from impactor stage 5 , corresponding to the minimum concentration of $\mathrm{Na}$ (Figure 7) and a minimum value for the largest particles from impactor stage 1 . However, these minimum values $(100,000-200,000)$ are 1 order of magnitude higher than the highest values observed on sea-salt particles 


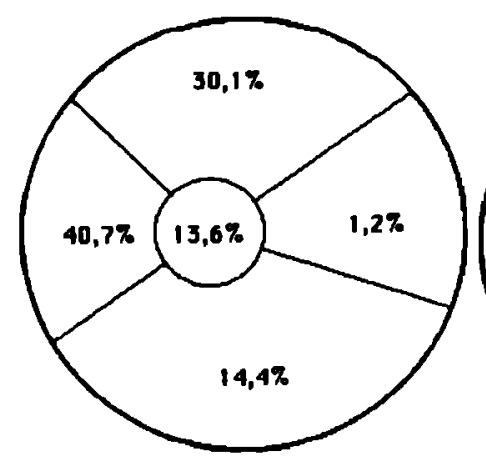

a.

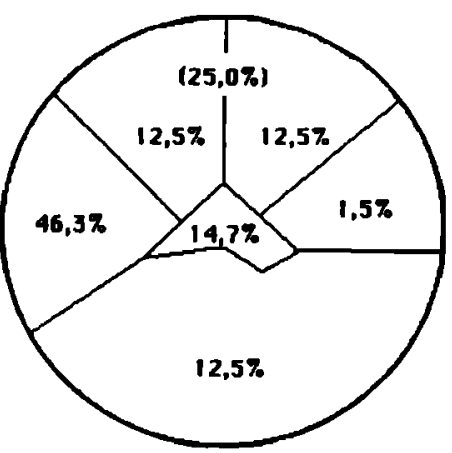

b.

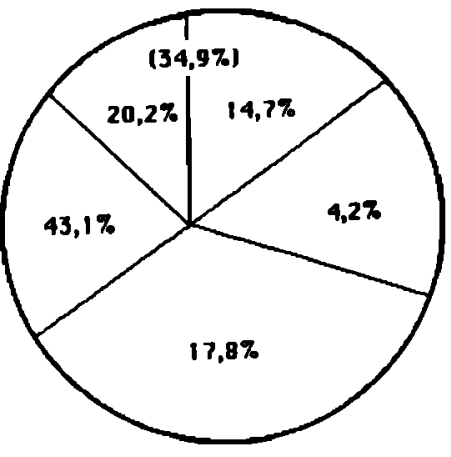

c.

Fig. 8. Comparison of airflow climatologies and airflow during sampling. Figures $8 \mathrm{a}$ and $8 \mathrm{c}$ show comparison of airflow climatologies by Miller, and Martin and Strauss respectively [GESAMP, 1985]. Figure 8b shows airflow during sampling, this work.

produced by in situ bubbling [Weisel, 1978, 1981]. The contribution of recycling from the sea surface to $\mathrm{Pb}$ or $\mathrm{Cd}$ concentrations is therefore less than $10 \%$ of their concentrations on the aerosol particles more than $7 \mu \mathrm{m}$ in diameter. Moreover, it can be seen that the very high $\mathrm{Br}$ and $\mathrm{Na}$ concentrations observed for sample PHYCEMED 81/13 do not correlate with high $\mathrm{Cd}$ or $\mathrm{Pb}$ concentrations.

Once $\mathrm{Cd}$ and $\mathrm{Pb}$ have been demonstrated to originate from anthropic pollution in the western Mediterranean aerosol, we may consider if they are tracers of specific sources. Pacyna et al. [1984], who calculated the yearly emissions of trace elements by anthropic sources in Europe, found that $80 \%$ of the Cd derives from primary nonferrous metal production ( $\mathrm{Zn}-\mathrm{Cd}$ and $\mathrm{Cu}-\mathrm{Ni}$ smelters) and that $60 \%$ of the $\mathrm{Pb}$ derives from gasoline combustion, the other sources emitting at least 5 times less. As a matter of fact, $\mathrm{Br}$ can be used as a secondary tracer for the gasoline
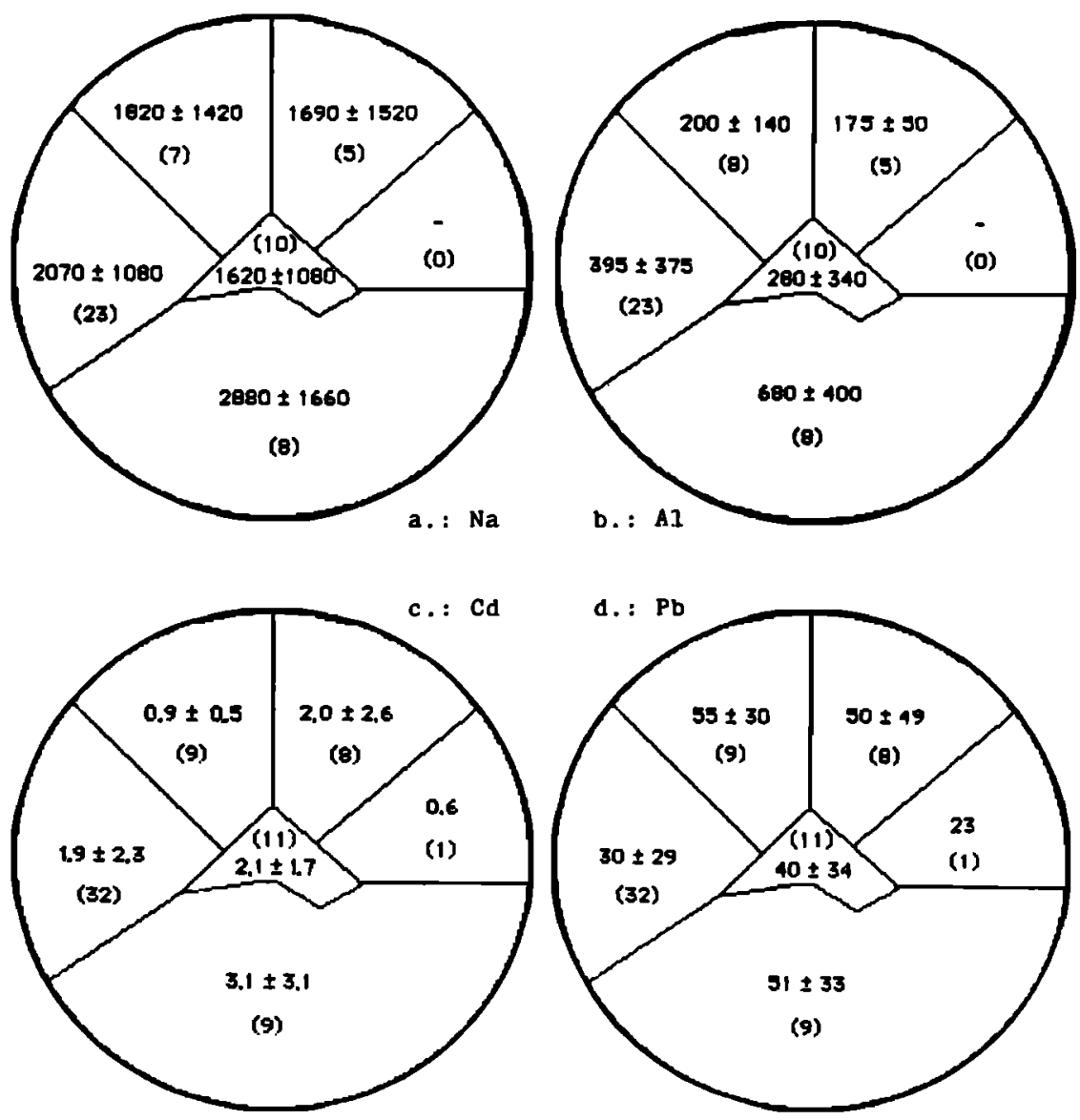

Fig. 9. Mean atmospheric concentrations in the western Mediterranean and standard deviations (in) nanograms per cubic meter) according to the sector of air mass trajectory (number of observations between brackets): (a) $\mathrm{Na}$; (b) $\mathrm{Al}$; (c) $\mathrm{Cd}$; and (d) $\mathrm{Pb}$. Respective average concentrations plus or minus standard deviations are $1960 \pm 1300 \mathrm{ng} \mathrm{m}^{-3}, 325 \pm 325 \mathrm{ng} \mathrm{m}^{-3}$, $1.9 \pm 2.1 \mathrm{ng} \mathrm{m}^{-3}$, and $39 \pm 32 \mathrm{ng} \mathrm{m}^{-3}$. 
TABLE 3. Mean Atmospheric Concentrations According to Distance of Air Transport and Enission Area

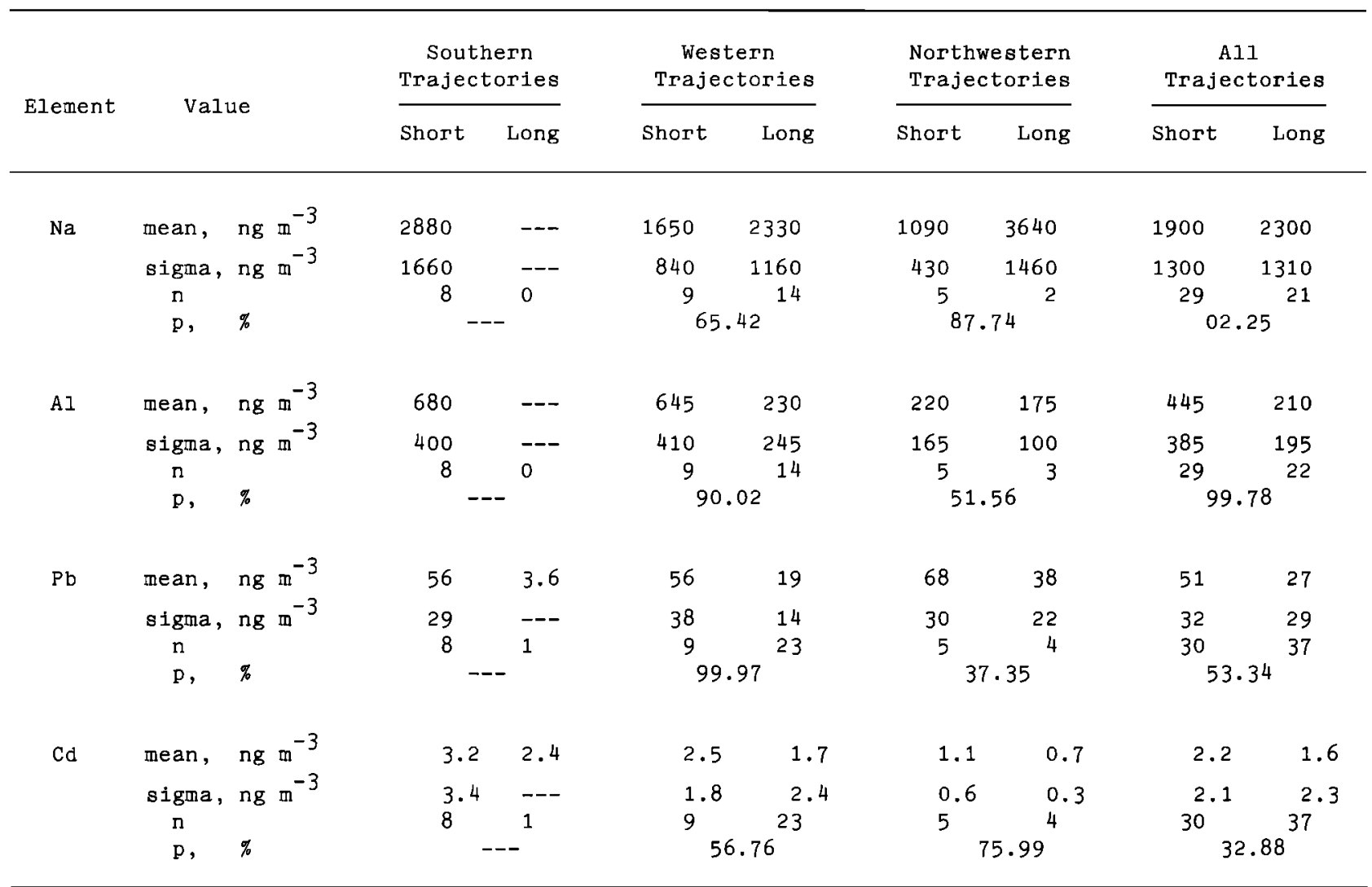

Here $n$ is the number of values; $p$, the probability of difference between the two means after an analysis of variance (see text).

combustion source, as it is added together with lead in gasoline [Elichegaray, 1980]. However, $\mathrm{Br}$ is also emitted by the marine source [Rahn, 1976]. Our results indicate that $\mathrm{Br}$ is not enriched relative to seawater composition (Table 4). However, halogens are known to be depleted relative to $\mathrm{Na}$ in the marine aerosol, as a result of their volatility and exchange between the particulate and the vapor phase [Kritz and Rancher, 1980]. We could consider that $\mathrm{Br}$ from pollution is associated with the fine aerosol fraction and the $\mathrm{Br}$ from marine origin with the coarse fraction, as its mass-size distribution exhibits one maximum concentration for each of these size classes (Figure 7). Morever, impactor stages 1-3 exhibit a depletion of $\mathrm{Br}$ relative to $\mathrm{Na}_{m}$ and seawater composition, while significant enrichments occur on the stage 5 and final filter (Table 5). Nevertheless, the volatilizationrecondensation process should lead to the transfer of some $\mathrm{Br}$ of marine origin from coarse to fine particles. It is therefore not possible to clearly distinguish between marine and pollution influences on $\mathrm{Br}$ concentrations, but we can express such a mixed origin by the following formula:

$$
\mathrm{Br}=\mathrm{a} \times \mathrm{Na}_{\mathrm{m}}+\mathrm{b} \times \mathrm{Pb}
$$

in which $\mathrm{Br}, \mathrm{Na} m$, and $\mathrm{Pb}$ are the concentrations of the respective elements; $\mathrm{a}$ is the $\mathrm{Br} / \mathrm{Na}$ ratio in the sea-salt particles, assumed to be 0.0062 as in seawater [Quinby-Hunt and Turekian, 1983]; and b is the $\mathrm{Br} / \mathrm{Pb}$ ratio in the particles from vehicle exhaust, ranging from 0.13 to 0.39 [Elichegaray, 1980], while the mean value for urban aerosol is 0.1 [Rahn, 1976]. The preceeding formula can be expressed as:

$$
\mathrm{Br} / \mathrm{Na} a_{m}=a+b \times P b / N a m
$$

Using the available results (55 samples) the computation of a linear regression between $\mathrm{Br} / \mathrm{Na}_{m}$ and $\mathrm{Pb} / \mathrm{Na}_{m}$ has given: $\mathrm{a}=4.54 \times 10^{-3} ; \mathrm{b}=$ 0.124 ; and $r^{2}=0.775$ (probability $>99.9 \%$ ). These values for $a$ and $b$ are quite consistent with the predicted values, allowing for the $\mathrm{Br}$ volatility. These results confirm the role of $\mathrm{Pb}$ as a tracer of leaded gasoline combustion and suggest a significant influence of this source on $\mathrm{Br}$ concentrations. Assuming that the $\mathrm{Br}$ load from gasoline combustion is given by $0.124 \times \mathrm{Pb}$, the contribution (in percent) of this source to total atmospheric $\mathrm{Br}$ is $12.4 \times \mathrm{Pb} / \mathrm{Br}$. We calculated that, on the average, $44 \%$ ( $\sigma=27 \%$ ) of $\mathrm{Br}$ in the western Mediterranean aerosol is due to long-range transport from continental urban sources. This is much higher than over remote marine regions. Indeed, data of Duce et al. [1983] indicate that this influence is rarely as high as $0.5 \%$ in the tropical Pacific aerosol.

When considering the atmospheric concentrations of pollutionderived elements in several regions (Figure 10), the western Mediterranean aerosol pollution level appears intermediate between remote and continental urban or industrial aerosols. The variability is such that concentrations may be as low as over the remote North Atlantic [Buat-Ménard, 1979] or as high as over polluted areas [Rahn, 1976; Viala et al., 1981; Gomes, 1984]. High concentrations should therefore be explained by the proximity of continental sources. As a matter of fact, it can be seen that the atmospheric concentrations are generally higher over the North Sea. This is consistent with the fact that countries bordering the North Sea are likely to be stronger sources than those bordering the Mediterranean basin [Pacyna, 1984, 1985].

\section{Influence of Sectors of Air Trajectories on the Aimosoheric Concentrations}

In the following section, geochemical informations and air mass trajectories will be used to provide evidence that changes in source 


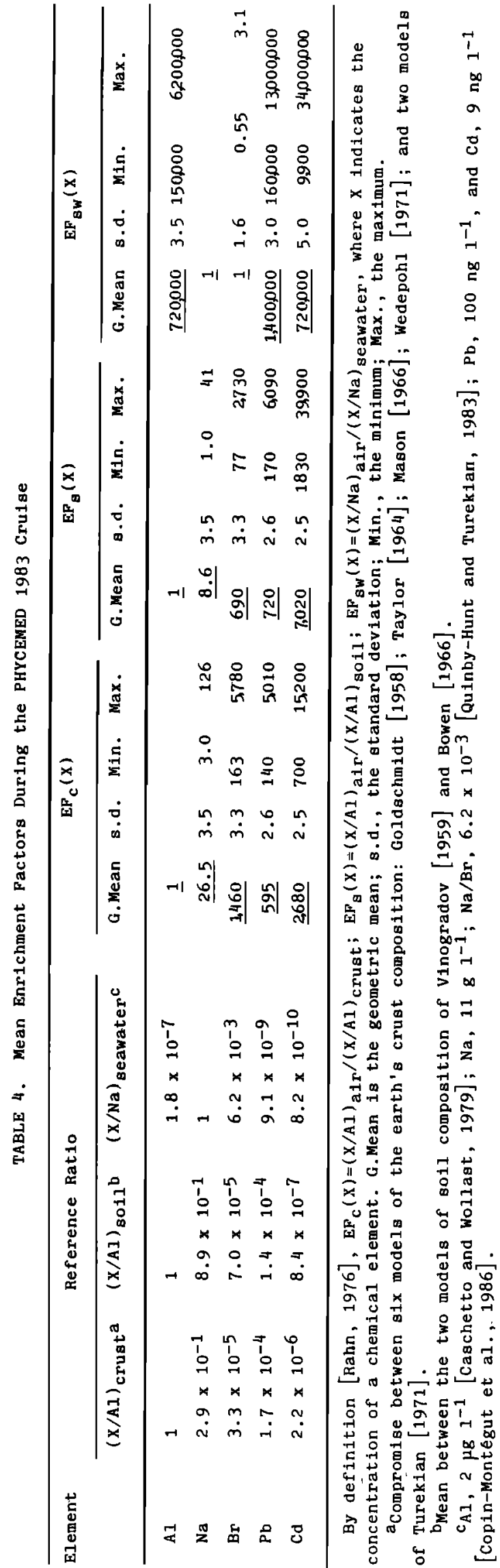

strengths, source regions, and airflow patterns are the reasons for the observed variability of atmospheric concentrations. It is noteworthy that observed average concentrations from each sector (Figure 9) may not be statistically representative of the yearly averages, because of the low number of samples associated with the different sectors. However, every standard deviation from Figure 9 or Table 3 is systematically high, suggesting that the same variability can be expected whatever the source region of the aerosol particles and their distance of transportation. Indeed, changes in source strengths, air mass dilution, or precipitation are likely to induce such a variability for limited source areas, while changes in airflow patterns (short/long-range transport from different source regions) induce changes in the mean atmospheric load. Such a variability is not observed as strongly over the remote ocean [Duce et al., 1983]. Air mass trajectories show that single changes in Mediterranean airflow patterns can occur temporarily for $\mathbf{1}$ or $\mathbf{2}$ days, for instance, because of a local low-pressure cell. Thus daily sampling is quite adapted to provide evidence of airflow and concentration variability in this region.

Sodium. Our data of $\mathrm{Na}$ atmospheric concentrations in the western Mediterranean Sea (Table 1) are very close to those reported from 13 samples by Prospero [1979]: our respective observation range is 155-5470 and 510-3450 $\mathrm{ng} \mathrm{m}^{-3}$, and arithmetic means are 1955 and $2135 \mathrm{ng} \mathrm{m}^{-3}$. In fact, it has been observed that atmospheric $\mathrm{Na}$ concentrations over the sea are exponentially related to the wind speed [Woodcock, 1953; Lovett, 1978], and this has been verified over the western Mediterranean [Arnold, 1985]. After the AOV, the probability that the mean concentrations for the various sectors (Table 2) are different is only $54 \%$, and this homogeneity reinforces the idea that $\mathrm{Na}$ results from a local sea-salt production and not from long-range transport. Moreover, AOV shows that there is no difference between the two groups of short and long trajectories (probability of difference: $2.25 \%$; Table 3).

Aluminium. Contrary to $\mathrm{Na}$, a significant influence of the air mass origin on the atmospheric Al load (Figure 9) is clearly indicated by AOV (probability: $99.88 \%$ ). The mean value for aerosols from the south $(680$ $\left.\mathrm{ng} \mathrm{m}^{-3}\right)$ is more than twice the mean value observed for the whole sample set $\left(325 \mathrm{ng} \mathrm{m}^{-3}\right)$. The west sector is also characterized by a high value ( $395 \mathrm{ng} \mathrm{m}^{-3}$ ) compared to the three other sectors (probability: 99.94\%).

Our sampling exhibits three episodes of high dust transport: PHYCEMED 81/01-04; ALBORAN 81/02-03, and PHYCEMED 83/04-07 (Figure 6). However, only the first two observed episodes seem to be related to transport from North Africa, as shown by air mass trajectories and satellite imagery [M. Desbois, personal communication, 1985]. The third episode appears related to soil dust transport from southern Spain and suggests that Spain also contributes to large inputs of soil materials to the western Mediterranean.

Cadmium. Values from the west, Northeast, and Mediterranean sectors are close to the mean of the whole sample set $\left(1.9 \mathrm{ng} \mathrm{m}^{-3}\right)$. The mean value from the northwest sector is significantly low compared to these three sectors (probability: $99.90 \%$ ) and could be related to the lowest anthropic source strengths of $\mathrm{Cd}$ in southern France compared to the Spanish or Italian source strengths [Pacyna, 1985]. The mean value from the south sector appears higher than the mean from the three above-mentioned sectors. Although the difference may not be statistically significant (probability of difference: $85.14 \%$ ), the presence of $\mathrm{Zn}-\mathrm{Cd}$ metallurgy in North African countries and the production of Cd-containing fertilizers in North Tunisia suggest that anthropic pollution are likely to be responsible for the high Cd concentrations from the south sector.

Lead. The mean values from the different sectors are close to the mean of the whole sample set $\left(39 \mathrm{ng} \mathrm{m}^{-3}\right)$. The probability that values from the various sectors are different is only $59 \%$. This situation should be related to the diffuse nature of $\mathrm{Pb}$ sources. Once again, it is noticeable that the south sector is not characterized by a low value. This might not be expected, since leaded gasoline consumption in North African countries (Morocco, Algeria, Tunisia and Libya) is about 4 times less than in Spain, France, and Italy (OCTEL data). However, emissions are likely to take place in coastal areas in North African countries, while the emisions are highly scattered throughout the European countries [Pacyna, 1985]. 
TABLE 5. Enrichment Factors and Particle Size Fractions for $\mathrm{Cd}, \mathrm{Pb}$, and $\mathrm{Br}$

\begin{tabular}{|c|c|c|c|c|c|}
\hline \multirow{2}{*}{$\begin{array}{c}\text { Impactor } \\
\text { Stage }\end{array}$} & \multicolumn{2}{|c|}{ PHYC 83/I 3-4-5 } & \multicolumn{2}{|c|}{ PHYC 83/I 17} & \multirow{2}{*}{$\frac{8 \text { samples }}{\mathrm{EF}_{\mathrm{sw}}(\mathrm{Br})}$} \\
\hline & $\begin{array}{c}\mathrm{EF}_{s w}(\mathrm{Cd}) \\
\left(\times 10^{-5}\right)\end{array}$ & $\begin{array}{l}\mathrm{EF}_{\mathrm{sw}}(\mathrm{Pb}) \\
\left(\mathrm{x} 10^{-5}\right)\end{array}$ & $\begin{array}{c}\mathrm{EF}_{\mathrm{sw}}(\mathrm{Cd}) \\
\left(\mathrm{x} \quad 10^{-5}\right)\end{array}$ & $\begin{array}{l}\mathrm{EF}_{\mathrm{sw}}(\mathrm{Pb}) \\
\left(\mathrm{x} \quad 10^{-5}\right)\end{array}$ & \\
\hline 1 & 2.0 & 1.8 & $\ldots$ & 1.4 & 0.63 \\
\hline 2 & 1.9 & 3.2 & 2.5 & 18 & 0.50 \\
\hline 3 & 8.5 & 13 & 5.0 & 50 & 0.65 \\
\hline 4 & 14 & 80 & 32 & 130 & 5.6 \\
\hline 5 & 85 & 740 & 300 & 1500 & 91 \\
\hline F & 29 & 500 & 71 & 740 & 29 \\
\hline All stages & 4.3 & 20 & 12 & 88 & $\ldots$ \\
\hline Bulk filters & 19 & 18 & 18 & 120 & 1.15 \\
\hline
\end{tabular}

\section{Influence of Airflow Patterns}

Influence of the distance of transport on $\mathrm{Pb} / \mathrm{Cd}$ ratio. It can be seen in Figure 6 that concentrations of elements of continental origin (Al, $\mathrm{Pb}, \mathrm{Cd}$ ) often vary in phase, suggesting changes in source strength or in polluted air mass dilution. However, sometimes variations are not in phase, suggesting a change in source region. The PHYCEMED 83/06 sample presents such a specific variation in Cd concentrations, showing the influence of a source region having a specific source of $\mathrm{Cd}$. The mapping of European anthropic emissions with a $1.5^{\circ}$ grid net [Pacyna, 1985] indicates that such regions exist and supports this hypothesis to explain the variability of interelemental ratios. Rahn [1981] used the ratio of noncrustal $\mathrm{Mn} / \mathrm{V}$ to characterize several geographical source regions for the Arctic aerosol, and it has been shown that such ratios could be used as regional tracers [Rahn and Lowenthal, 1984; Thurston et al., 1985].

We applied such an approach using the $\mathrm{Pb} / \mathrm{Cd}$ ratio. Indeed, this ratio does exhibit large variations according to the aerosol sources and, subsequently, in the marine aerosol, due to the different natures of the sources for these elements: diffuse for $\mathrm{Pb}$ and localized for $\mathrm{Cd}$ [Pacyna, 1983, 1985]. Pacyna's [1983] results show that low values (5-15) can be expected in aerosols emitted by nonferrous metallurgy (Cd source), while very high values $(2,300)$ can be expected in aerosols from gasoline combustion ( $\mathrm{Pb}$ source). Intermediate values are found in remote continental (64) or marine (26) aerosols [Rahn, 1976], and the mean ratio for the anthropic European emissions is 46 [Pacyna, 1983]. We present in Figure 11 the $\mathrm{Pb}$ versus $\mathrm{Cd}$ concentrations from our sample set. It can be seen that most values of the $\mathrm{Pb} / \mathrm{Cd}$ ratio range from 15 to 60 (arithmetic mean: 46; geometric mean: 24), thus tracing any mean or background aerosol. However, a few samples exhibit either high or low single values that should be attributed to aerosols from coastal pollution sources that were neither mixed nor diluted. Moreover, the highest values (170-230) may be attributed to large coastal urban areas, and the lowest to Cd-refining centers that can be found, for instance, near the coasts of southeast Spain or North Africa.

Influence of the distance of transport on short and long traiectories. Table 3 shows that the mean atmospheric concentrations of $\mathrm{Al}, \mathrm{Pb}$, and Cd are 110,90 , and $40 \%$ higher, respectively, when associated to close emission areas. This is only a rough estimation of the contributions from far away and close source regions, as air masses coming from far away are also loaded by close emission areas, which leads to reduced differences. Although the probability of a difference between short and long trajectories is sometimes low, especially for $\mathrm{Cd}$ (see Table 3), the difference should be significant, at least for $\mathrm{Al}$ and $\mathrm{Pb}$. Indeed, the highest concentrations associated with short-range transport are observed for each of the three sectors (south, west, and northwest) divided in close and far parts (Table 3). Such a difference can be explained by the lowest diffusion occurring, in the case of weak winds, and by the fact that meteorological situations associated with short-range transport should mainly be nonfrontal and consequently occur in the absence of precipitation.

Influence of the airflow level. Variable level air mass trajectories give us the means to study the influence of the altitude of transport on the observed atmospheric load. Indeed, we can believe that the influence of emission sources will be at a maximum when air is transported within the boundary layer and at a minimum when transport occurs in the upper troposphere. Eliassen [1978] has assumed a 1000-m height for the boundary layer over Europe. In the present work we have assumed an average height of $1500 \mathrm{~m}(800 \mathrm{hPa})$ in order to take into account orographic effects around the basin. Variable level trajectories were computed for 40 sampling periods. Only $15 \%$ of them exhibit transport over $1500 \mathrm{~m}$ during the 3 days before sampling. The frequency of anticyclonic transport showing permanent flowing down of air is even lower, so that we are not able to present a statistical study of the respective influence of cyclonic/anticyclonic transport. Nevertheless, we present here some cases which illustrate the interest of coupling geochemical and trajectographic information, in particular, to point out source areas.

The influence of local coastal sources on atmospheric concentrations during sampling associated with long-range air transport over 4 days can be illustrated by the PHYCEMED 83/17 sample. This sample exhibits the highest of our observed $\mathrm{Pb}$ concentrations (Table 1) and the highest concentrations of other pollution tracers during the cruise (Figure12): nonmarine $S\left(S_{x s} ; G\right.$. Bergametti, personal communication, 1986), and noncrustal $\mathrm{Mn}$ and $\mathrm{V}\left(\mathrm{Mn}_{\mathrm{XS}}\right.$ and $\mathrm{V}_{\mathrm{xS}}$; [Dulac, 1986]). The associated trajectory shows transport from the northeast sector (Figure12). Un the other hand, it can be seen in Figure 12 that sample 15, filtered 3 days before, is associated with a similar northeast trajectory but exhibits the lowest concentration of $\mathrm{Cd}, \mathrm{Pb}$, and $\mathrm{V}_{\mathrm{xs}}$ during the PHYCEMED 83 cruise. A more precise look at the levels of air transport shows that the highest concentrations of sample 17 can be attributed to the long residence time of the air in the lower troposphere, where pollutants are emitted. Moreover, this air mass was transported over populated and industrialized areas of North Italy and the southeastem French coast. For sample 15 the sampled air mass had only spent a few hours at low level and mostly over the sea. The relatively low concentrations observed 

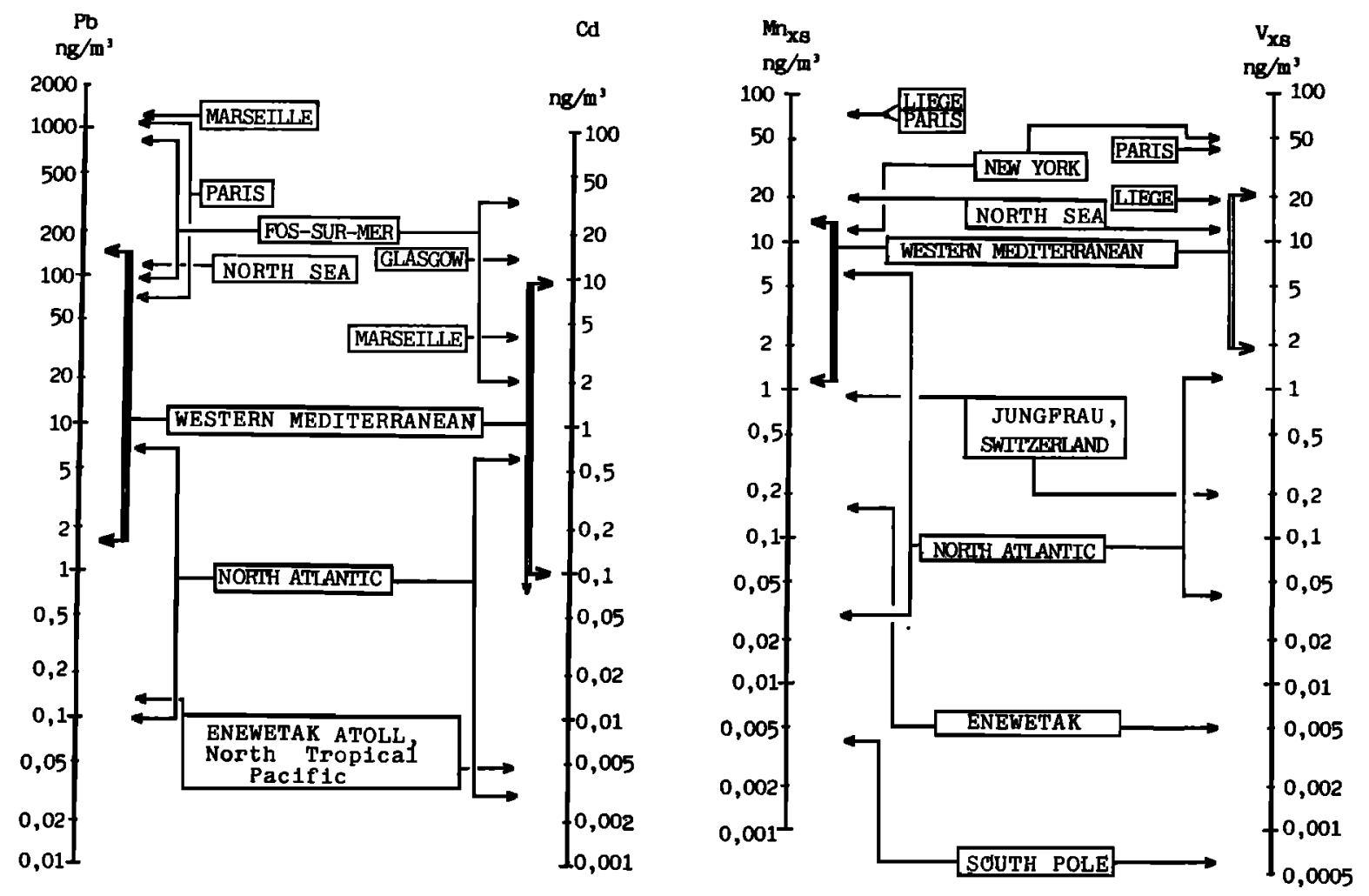

Fig. 10. Pollutant atmospheric concentrations in some marine and continental environments. References: south pole [Zoller et al., 1974]; Enewetak Atoll [Duce et al., 1984]; North Atlantic [Duce and Hoffman, 1976; Duce et al., 1976a]; western Mediterranean, this work; North Sea [Peirson et al., 1974; Rahn, 1981]; Fos-sur-Mer [Gomes, 1984]; Marseille [Viala et al., 1981]; Paris Rahn, 1981; Koutrakis, 1984]; Glasgow [McDonald and Duncan, 1978]; Jungfrau, Liege and New York, after Rahn's [1981] compilation.

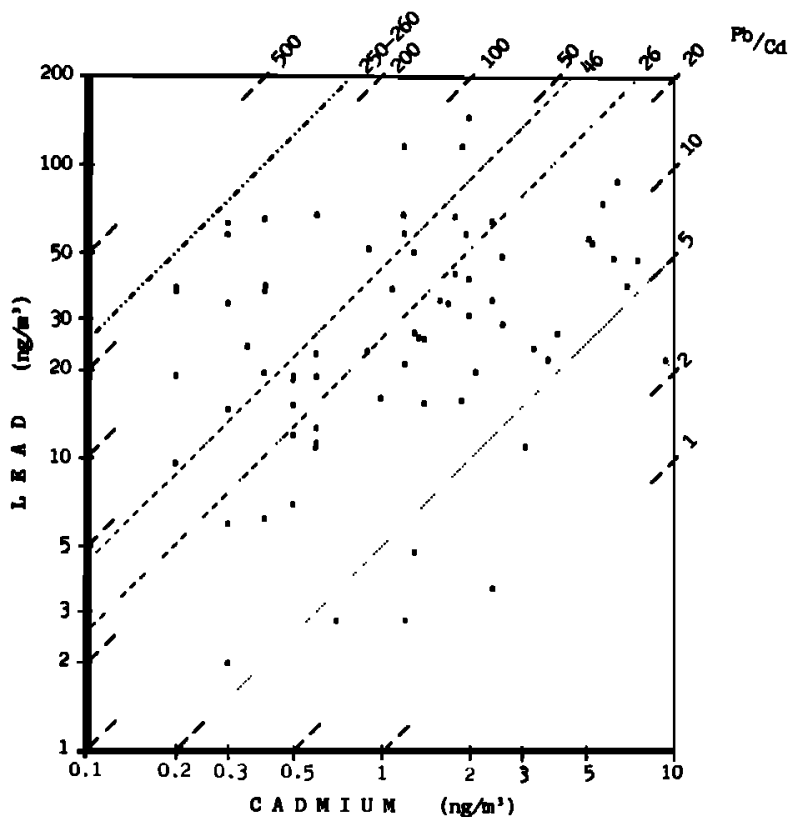

Fig. 11. $\mathrm{Pb}$ versus $\mathrm{Cd}$ concentration in the western Mediterranean aerosol: urban aerosol [Rahn, 1976]; mean for European anthropic emissions [Pacyna, 1983]; remote marine aerosol [Rahn, 1976]; mean aerosol from European Zn-Có smelters [Pacyna, 1983]. should therefore not reflect a local origin as for sample 17 but the dilution of an air mass originating from eastern Europe. This interpretation is also supported by recent measurements of the isotopic composition of $\mathrm{Pb}$, which have been performed on fractions of filter samples 15 and 17 [Maring et al., 1987].

Besides sample 15, the lowest concentrations of pollutants during the PHYCEMED 83 cruise have been observed for samples 09,11 and 12 (Figure 6). The associated trajectories (Figures 13 and 14) show that the air mass traveled over $850 \mathrm{hPa}(1500 \mathrm{~m})$ or did not travel over land under this level. It is possible to ascribe the $\mathrm{Pb}$ and $\mathrm{Cd}$ concentration peak of sample 10 (Figure 6) to the flow over industrialized south Sardinia under the $1000 \mathrm{~m}$ level, followed by a stay over the northem Tunisian coast (Figure 13). Such cases illustrate the validity of computed back trajectories and the help they can provide to assess the daily concentration variability. Moreover, they point out the influence of the level of air during transport on the observed atmospheric load.

Despite the interest in using variable level trajectories, a few cases could be found showing disagreement between trajectories and geochemical observations. Most of these cases are associated with rain events during the PHYCEMED 81 cruise [Dulac, 1986]. Indeed, the computed trajectories do not give indications of the precipitations that the air could have encountered during its transport, and the wash-out of aerosol particles by rain is likely to decrease atmospheric concentrations [Hirsch et al., 1981; Parungo et al., 1984]. Such decreases cannot be explained by air mass trajectory alone. Meteorological maps or in situ observations during sampling should be used to verify the probability of rain. The grid of meteorological observations (scale of synoptic fields data greater than $200 \mathrm{~km}$ ), in particular over seas, is too large to take into account localized meteorological phenomena such as storms, 


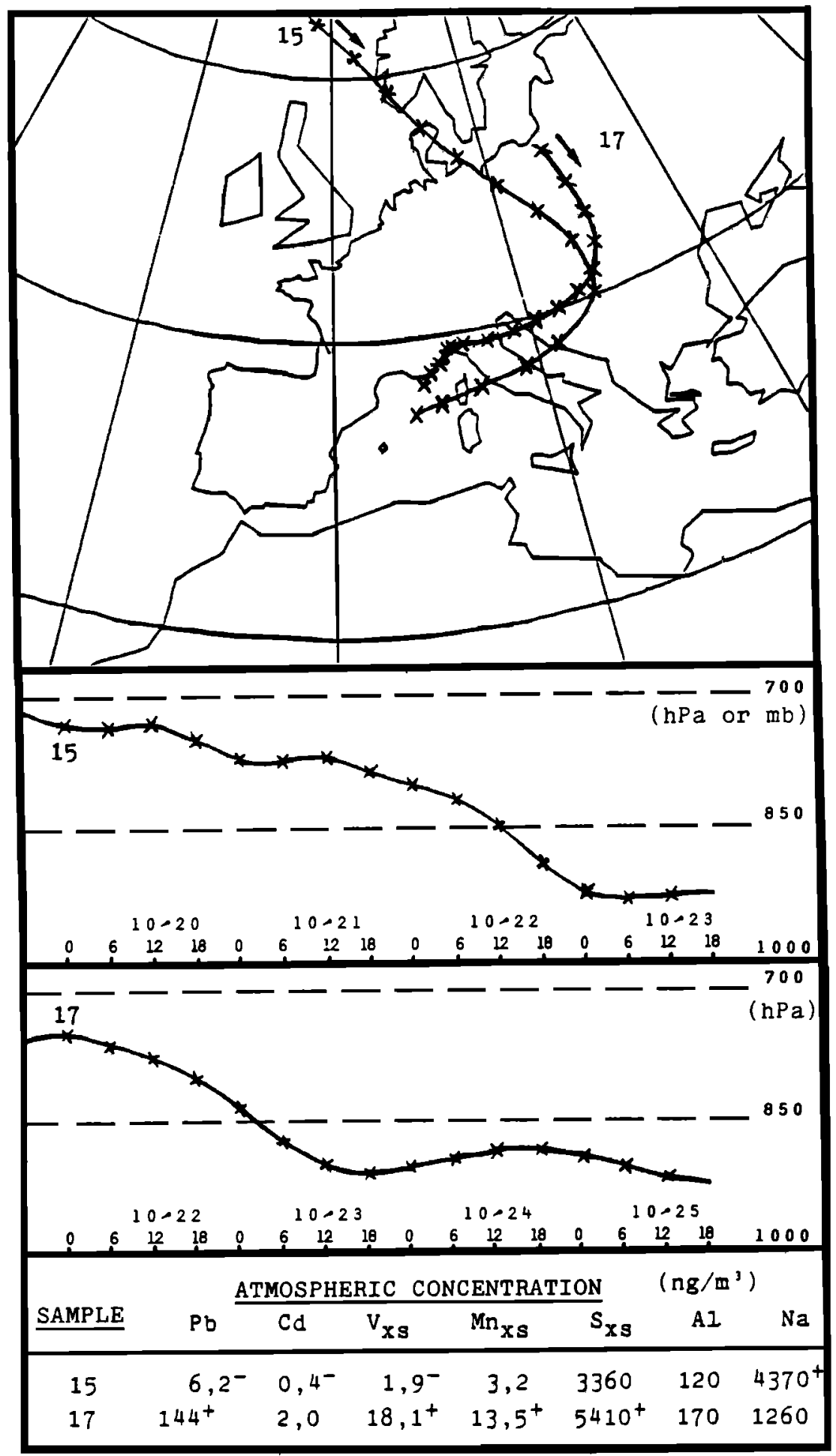

Fig. 12. Air mass trajectories and atmospheric concentrations for samples PHYCEMED 83/15 and 17 (6-hour period between successive crosses on trajectories).

orographic winds or coastal breezes. For instance, there are some cases of high Na concentrations associated with high wind speeds at sea level, while trajectories show short-range transport likely to be associated with low wind speeds. Such remarks demonstrate that care is needed when using trajectories and confirm their inaccuracy for rainy situations [Artz et al., 1985].

\section{Contributions From the Different Source}

Regions to the Trace Metal Inputs to the

Western Mediterranean Atmosohere

We used the observed mean concentrations for each sector previously discussed in order to estimate the relative influence of the different source 


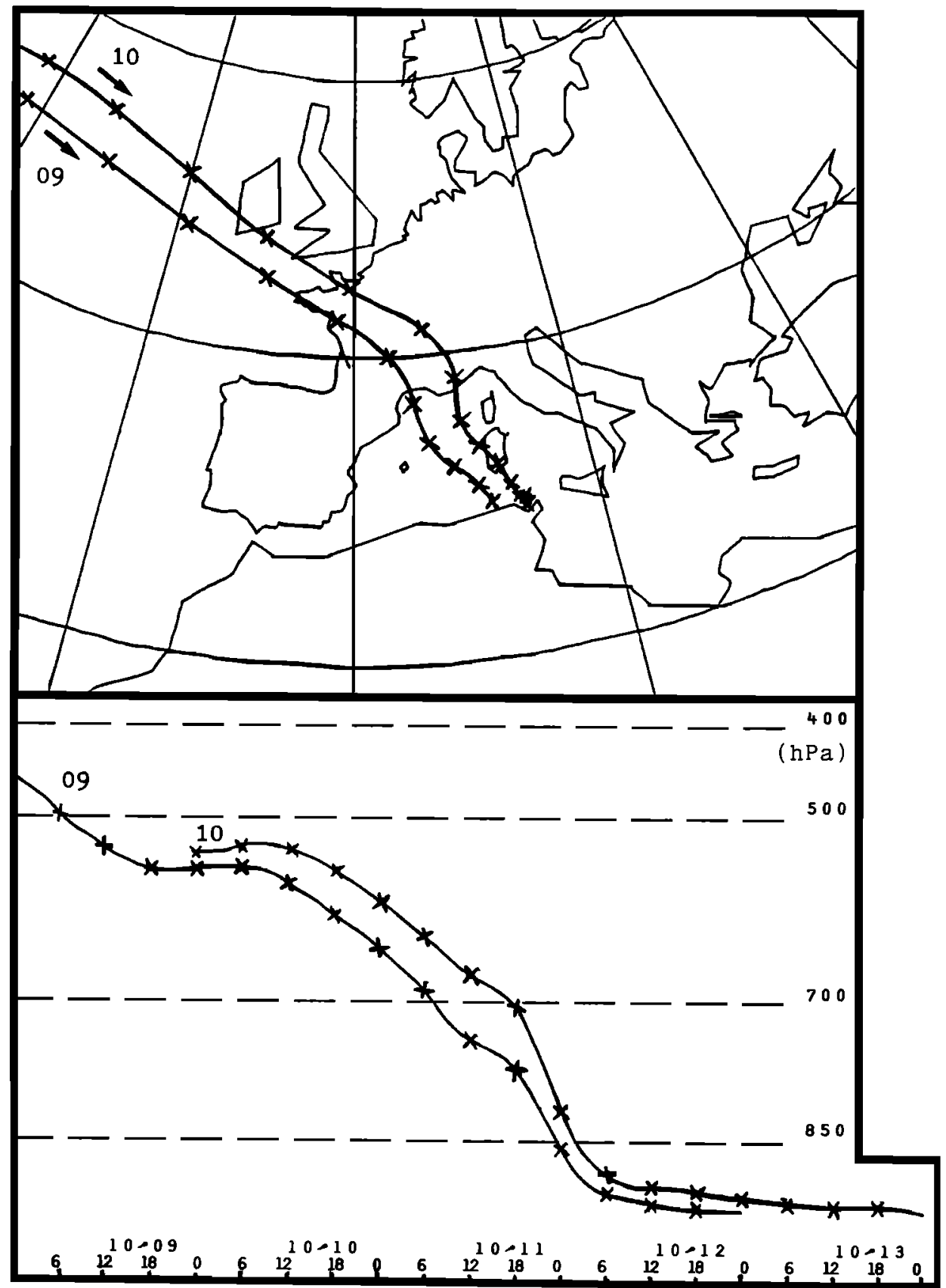

Fig. 13. Air mass trajectories associated with samples PHYCEMED 83/09 and 10 .

regions on the mean atmospheric concentrations over the Western Mediterranean. It has been assumed that the input of a given element from a given source region is proportional to the product of its mean concentration by the frequency of transport from the associated sector. According to the results of airflow patterns given in Figure 8, the following frequencies of transport have been assumed: west, $41 \%$; northwest, $16 \%$; south, 15\%; Mediterranean, $14 \%$; northeast, $12 \%$; and east, $2 \%$. The contribution from the east sector was considered to be negligible. Results of respective contributions of each sector to the inputs of $\mathrm{Al}, \mathrm{Cd}$, and $\mathrm{Pb}$ are presented in Figure 15. Because of the dominant westerly flow, the Iberian Peninsula and southwestern France are likely to be the prevailing providers of atmospheric trace metals to the western Mediterranean atmosphere on a yearly time scale. As the aerosol residence time may be longer than 4 days, especially for the fine particles, air masses whose trajectories are limited to the Mediterranean local sector are probably loaded with particles both from Italy and other further emission sources. Hence Westem Europe should provide about $55-60 \%$ of the atmospheric mineral material over the basin, while 20-30\% would be transported from Africa.

Heavy metals. Our calculations indicate that $30-40 \%$ of the $\mathrm{Pb}$ and Cd over the Western Mediterranean derives from southwestern Europe (west sector). However, the major feature of Figure 15 is that transport from North Africa is as high as $20-25 \%$ of the total and is equal to or higher than transport from any other emission area except the west. This means that heavy metal pollution by North African countries is not a myth and should definitely be considered. The extrapolation of such a 


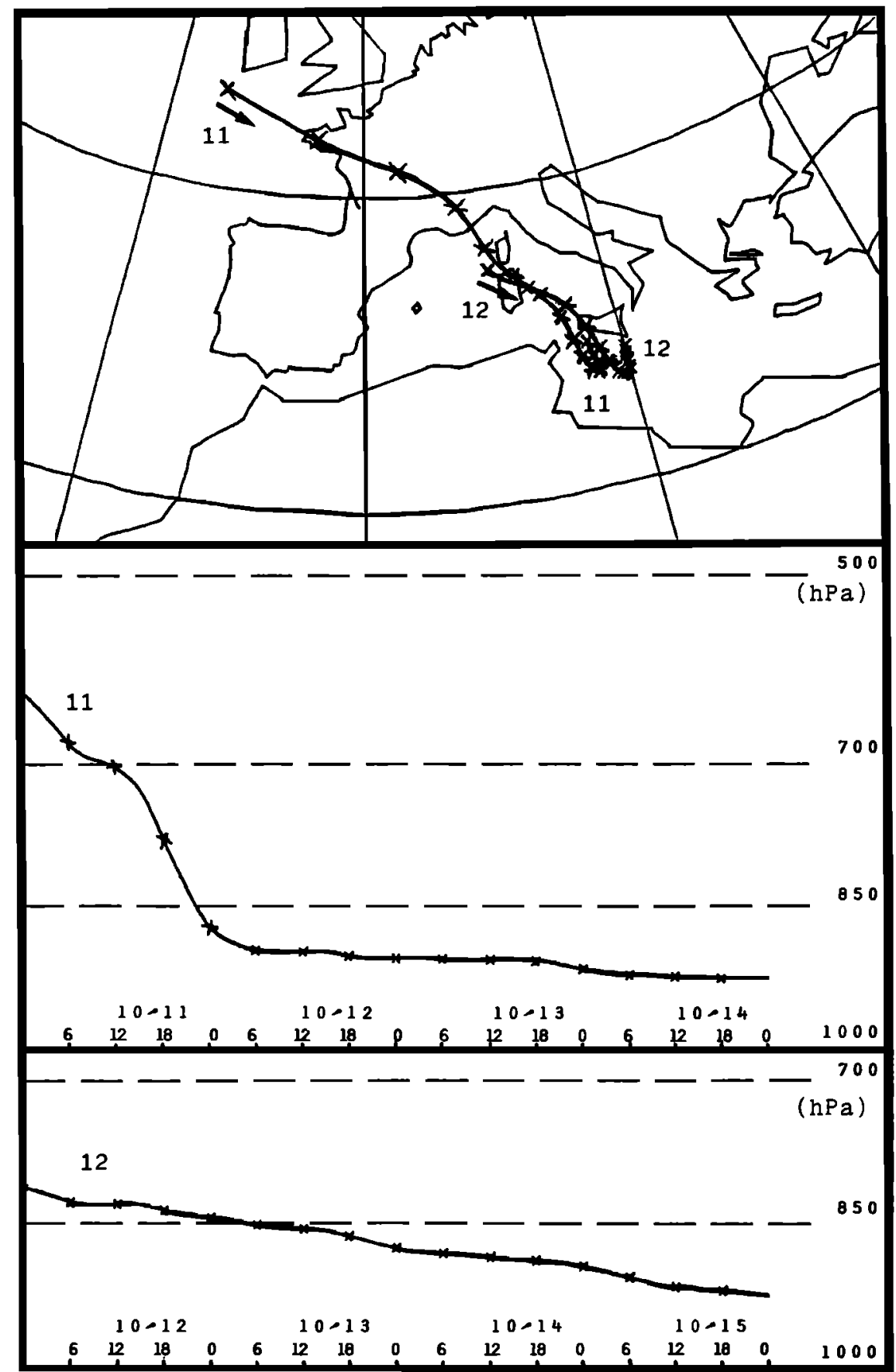

Fig. 14. Air mass trajectories associated with samples PHYCEMED 83/11 and 12.

conclusion to a yearly time scale will require a careful evaluation of the effect of seasonal changes in source strengths for each source region and, particularly, the effect on $\mathrm{Pb}$ concentrations (see section 3).

Aluminium. It appears from our data set that $\mathrm{Al}$ transport from Africa to the western Mediterranean is lower than from southwestern Europe. However, although our sample set can be considered as representative of a yearly time scale on the basis of meteorological considerations, it has to be stressed that the concentration range of $\mathrm{Al}$ is probably not covered by our sampling, and this would particularly affect the mean value of the south sector. Indeed, the highest values observed in this work $\left(1100-1400 \mathrm{ng} \mathrm{m}^{-3}\right)$ are lower than reported values for Saharan dust transport episodes off Northwestern Africa (about 10,000 $\mathrm{ng} \mathrm{m}^{-3}$ [Prospero, 1979] or 5,170 $\mathrm{ng} \mathrm{m}^{-3}$ [Buat-Ménard, 1979]) and even over the Mediterranean Sea $\left(5,070 \mathrm{ng} \mathrm{m}^{-3}\right.$ over the Thyrrehenian
Sea [Chester et al., 1984] and about $8,000 \mathrm{ng} \mathrm{m}^{-3}$ over the northwest coast of Corsica in December 1985 (Bergametti, personal communication, 1986)). Thirty-four of such high dust transports have been registered over 10 years between 1968 and 1977 [Prodi and Fea, 1978]. Since such events may dominate the atmospheric input to the sea surface on a yearly time scale, only continuous sampling is likely to allow a determination of their frequency of occurrence and intensity.

\section{Conclusion}

This work was focused on the processes affecting the variability of atmospheric trace metal concentrations in the western Mediterranean Sea. $\mathrm{Al}, \mathrm{Br}, \mathrm{Cd}, \mathrm{Na}, \mathrm{Pb}$, and ${ }^{210} \mathrm{Po}$ concentrations from bulk filters and cascade impactor samples collected during five cruises (1980-1983) have 


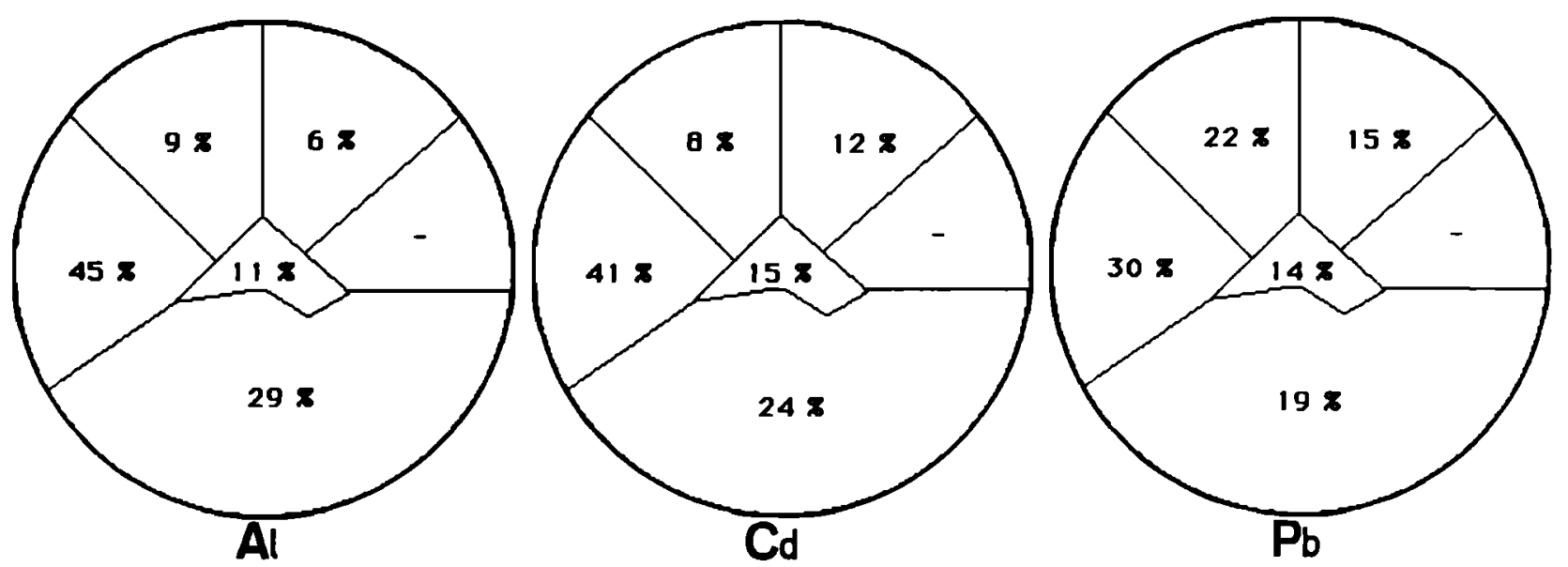

Fig. 15. Calculated influence of the different sectors on the input of $\mathrm{Al}, \mathrm{Cd}$, and $\mathrm{Pb}$ into the western Mediterranean atmosphere.

been used to characterize the aerosol sources: the marine source $(\mathrm{Na})$, the aeolian soil mobilization $(\mathrm{Al})$, anthropic sources $(\mathrm{Cd}, \mathrm{Pb})$, and the volcanic source $\left({ }^{210} \mathrm{Po}\right)$.

$\mathrm{Na}$ was verified as a convenient tracer for the marine aerosol source, except during high dust episodes when the crustal influence may account for more than $20 \%$ of its total concentration. Measurements of $210 \mathrm{Po}$ indicate that volcanic activity is a negligible source for $\mathrm{Cd}$ and $\mathrm{Pb}$ in the westem Mediterranean atmosphere, despite some sporadic influence in the Thyrrhenian Sea. Contrary to the observations made over the remote ocean, recycling of these heavy metals from the sea surface microlayer is negligible in the westem Mediterranean Sea, whatever the particle size fraction of the aerosol. As a consequence, $\mathrm{Cd}$ is likely to derive from anthropic industrial sources, known to be nonferrous metallurgy plants in Europe, and $\mathrm{Pb}$, as confirmed by correlation with $\mathrm{Br}$, from leaded gasoline combustion.

As shown by three-dimensional air mass trajectory analyses, the variability of daily atmospheric concentrations reflects both changes in continental source strengths and in airflow patterns. Moreover, the influence of close emission areas has been clearly pointed out. Average concentrations of elements from continental sources are $40-110 \%$ higher when the associated air mass trajectories are limited to the Mediterranean coastal countries over 4 days. Heavy metals concentrations may be 20 times higher when the air has been transported under the $1500 \mathrm{~m}$ level over anthropic sources, and the knowledge of the level of air transport allows us to precisely point out source regions. When sources are close enough, it is even possible to use a characteristic interelemental ratio, such as $\mathrm{Pb} / \mathrm{Cd}$, as a tracer for the kind of aerosol sources: urban sources are associated with the highest values of the ratio, typically about 200 , while the lowest, about 5 , would be due to industrial sources.

Finally, our data set has been used to evaluate the influence of the main aerosol source regions to the atmospheric burden over the Sea. Although southwestern Europe is responsible for the largest $\mathrm{Pb}$ and $\mathrm{Cd}$ inputs (30-40\%), due to the prevailing westerly flow, the inputs from North Africa are also significant (20-25\%). However, the existence of seasonal changes in pollution source strengths and sporadic but intense soil dust transport, suggests that only a continuous sampling strategy will enable us to assess the inputs of trace elements to the Western Mediterranean marine environment on a yearly time scale.

Acknowledgments. We wish to thank the staffs of R/V Le Noroît, Le Suroît and Le Cormide de Savedra for their logistical support during the cruises, and G. Revel, R. Delmas, D. Nau, and M. Piedalu from the Laboratoire Pierre Süe d'Analyse par Activation at Saclay for assistance and the use of facilities in activation analyses. We are grateful to C. E. Lambert, H. Cachier, A. Liabotis, N. Risler, A. Seghaier and A. Vigot for their assistance in sampling and analysis, to B. Strauss for providing air mass trajectories, and to J. Davies for correcting our manuscript. We also thank J. M. Miller, R. Chesselet, G. Bergametti and the reviewers for helpful discussions and suggestions. This work was supported by the Centre National de la Recherche Scientifique, the Commissariat à l'Energie Atomique, IFREMER, and the French Ministère de IEnvironnement (Contract 84122). This is C.F.R. contribution 773.

\section{References}

Arimoto, R., R. A. Duce, B. J. Ray, and C.K. Unni, Atmospheric trace elements at Enewetak Atoll, 2, Transport to the ocean by wet and dry deposition, J. Geophys. Res. 90, 2391-2408, 1985.

Amold, M., Géochimie et transport des aérosols métalliques au-dessus de la Méditerranée Occidentale, Thèse d'état, Univ. of Paris 7, 1985.

Amold, M., A. Seghaier, D. Martin, P. Buat-Ménard, and R. Chesselet, Géochimie de l'aérosol marin au-dessus de la Méditerrané occidentale, in Proceedings of VIe journées d'études sur les Pollutions Marines en Méditerranée, Cannes, pp. 27-37, Commission Internationale pour l'Exploration Scientifique de la Méditerranée (CIESM), Monaco, 1982.

Artz, R., R. A. Piekle, and J. Galloway, Comparison of the ARL/ ATAD constant level and the NCAR isentropic trajectory analyses for selected case studies, Atmos. Environ. 19, 47-63, 1985.

Blanchard, D. C., The production, distribution, and bacterial enrichment of the sea-salt aerosol, in Air-sea Exchange of Gases and Particles, edited by P. S. Liss and W. G. N. Slinn, pp. 407-454, D. Reidel, Hingham, Mass., 1983.

Bowen, H. J. M., Trace Elements in Biochemistry, Academic , Orlando, Fla., 1966.

Buat-Ménard, P., Influence de la retombée atmosphérique sur la chimie des métaux en trace dans la matière en suspension de l'Atlantique Nord, Thèse d'état, Univ. of Paris 7, 1979.

Buat-Ménard, P., and M. Arnold, The heavy metal chemistry of atmospheric particulate matter emitted by Mount Etna Volcano, Geophys, Res. Leth, 5, 245-248, 1978.

Buat-Ménard, P., and R. Chesselet, Variable influence of the atmospheric flux on the trace metal chemistry of oceanic suspended matter, Earth Planet. Sci. Lett. 42, 399-411, 1979.

Buat-Ménard, P., U. Ezat, and A. Gaudichet, Size distribution and mineralogy of alumino-silicate dust particles in Tropical Pacific air and rain, in Precipitation Scavenging. Dry Deposition. and Resuspension, vol. 2, edited by H. R. Pruppacher, R. G. Semonin, and W. G. N. Slinn, pp. 1259-1269, Elsevier, North-Holland, New York,1983.

Caschetto, S., and R. Wollast, Vertical distribution of dissolved aluminium in the Mediterranean Sea, Mar. Chem., Z, 141-155, 1979.

Chester, R., E. J. Sharple, G. S. Sanders, and A. C. Saydam, Saharan dust incursion over the Tyrrhenian Sea, Atmos. Environ., 18, 929-935, 1984. 
Copin-Montégut, G., P. Courau, and E. Nicolas, Distribution and transfer of trace elements in the western Mediterranean, Mar. Chem., 18. 189-195, 1986.

Currie, L.A., Limits for qualitative detection and quantitative determination. Application to radiochemistry, Anal. Chem, 40 , 586-593, 1968.

Dayan, U., J. M. Miller, W. C. Keene, and J. N. Galloway, An analysis of precipitation chemistry data from Alaska, Atmos. Environ., 19. 651-657, 1985.

Delmas R., F. Dulac, C. E. Lambert, and G. Revel, Neutron activation analysis: a simple versatile program for automated gamma spectrometry with a personal computer, L.Radioanal. Nuc. Chem., 111, 371-383,1987.

Duce, R. A., and G. L. Hoffman, Atmospheric vanadium transport to the ocean, Atmos. Environ, 10, 989-996, 1976.

Duce, R. A., G. L. Hoffman, and W. H. Zoller, Atmospheric trace metals at remote northern and southern hemisphere sites: pollution or natural?, Science $187,59-61,1976 a$.

Duce, R. A., et al., Trace metals in the marine atmosphere: Sources and fluxes, in Marine Pollutant Transfer edited by H. L. Windom and $R$. A. Duce, pp. 77-119, D. C. Heath, Lexington, Mass., 1976 b.

Duce, R. A., R. Arimoto, J. B. Ray, C.K. Unni, and P. J. Harder, Atmospheric trace elements at Enewetak Atoll, 1, Concentrations, sources, and temporal variability, L. Geophys. Res., 88, 5321-5342, 1983.

Duce, R. A., B. J. Ray, A. Hewitt, J. S. Williams, and R. Arimoto, Comparison of Enewetak and Samoa trace element data, Searex Newsletter, 7, 19-21, 1984.

Dulac, F., Dynamique du transport et des retombées d'aérosols métalliques en Méditerranée occidentale, Thèse de doctorat, Univ. of Paris 7, 1986.

Eliassen, A., The OECD study of long range transport of air pollutants: Long-range transport modelling, Atmos. Environ., 12, 479-487, 1978.

Elichegaray, C., Contribution à l'étude du comportement physico-chimique de l'aérosol urbain, Thèse $3 \mathrm{e}$ cycle, Univ, of Paris 7, 1980.

Ezat, U., Dosage du calcium particulaire dans l'eau de mer par spectrométrie d'absorption atomique sans flamme, Analusis, in press, 1987.

Joint Group of Experts on Scientific Aspects of Marine Pollution, Atmospheric transport of contaminants into the Mediterranean region. Rep. and Stud. GESAMP 26, 53 pp., World Meteorological Organization, 1985.

Girardi, F., G. Guzzi, and J. Pauly, Reactor neutron activation analysis by the single comparator method, Anal. Chem., 37, 1085-1092, 1965.

Goldschmidt, V. M., Geochemistry, 2nd ed., Int. Ser. Monogr. Phys., 741 pp., Oxford University Press, New York, 1958.

Gomes, L., Application d'un modèle de diffusion atmosphérique aux émissions particulaires du complexe industriel de Fos/Berre: Influence sur le cycle atmosphérique des métaux en Méditerranée occidentale, D.E.A. Rep., Univ. of Paris 7, 1984.

Henderson, R. G., and K. Weingartner, Trajectory analysis of MAP3S precipitation chemistry data at Ithaca, N.Y., Atmos. Environ., 16, $1657-1665,1982$.

Hidy, G. M., Aerosols - An industrial and environmental science, 774 pp., Academic, Orlando, Fla., 1984.

Hirsch, Y., M. Peleg, and M. Luria, Characterization of suspended dust in the Jerusalem air, Environ. Sci. Technol., 15, 1456-1460, 1981.

Knuth, R. H., Calibration of a modified Sierra Model 235 slotted cascade impactor, Rep. Environ. Meas. Lab., 24 pp., Natl. Tech. Inf. Serv., U.S. Dep. Commerce, Springfield, Va., 1979.

Koutrakis, P., Physico-chimie de l'aérosol urbain: Identification et quantification des principales sources par analyse multivariable, Thèse 3e cycle, Univ. of Paris 7, 1984.

Kritz, M. A., and J. Rancher, Circulation of $\mathrm{Na}, \mathrm{Cl}$, and $\mathrm{Br}$ in the tropical marine atmosphere, L. Geophys. Res. 85, 1633-1639, 1980.

Lambert, G., B. Ardouin, and G. Polian, Volcanic output of long-lived radon daughters, J. Geophys. Res., 87, 11,103-11,108, 1982a.
Lambert, G., G. Polian, J. Sanak, B. Ardouin, A. Jegou, and J.-C. Le Roulley, Cycle du radon et de ses descendants, application à l'étude des échanges trosphère-stratosphère, Ann. Géophys., 38, 497-531, $1982 \mathrm{~b}$.

Lorenc, A., I. Rutherford, and G. Larsen, The E.C.M.W.F. analysis and data assimilation scale analysis of mass and wind fields, E.C.M.W.F. Tech. Rep, 6, Eur. Cent. for Medium-Range Weather Forecasts, Reading, England, 1977.

Lovett, R.F., Quantitative measurement of airborne sea-salt in the North Atlantic, Tellus, 30, 358-363, 1978

Maring, H., D. M. Settle, P. Buat-Ménard, F. Dulac, and C. C. Patterson, Stable lead isotope tracers of air mass trajectories in the Mediterranean region, submitted to Nature, 1987.

Martin, D., D. Cheymol, M. Imbard, and B. Strauss, Classement automatique des trajectoires du Panache de l'Etna, Proceedings of the 3rd European Symposium on Physico-Chemical Behaviour of Atmospheric Pollutants, Varese, Italy, pp.509-525, D. Reidel, Hingham, Mass., 1984

Martin, D., C. Mithieux, and B. Strauss, Evaluation of the use of the synoptic vertical component in a transport trajectory model. Proceedings of the International Symposium on Acidic Precipitation, Muskoka, Canada, Atmos, Environ, 21, 45-52, 1987.

Mason, B., Principles of Geochemistry, 3rd ed., John Wiley, New York, 1966.

McDonald, R. L., and A. M. Duncan, Variability of atmospheric levels of metals in an industrial environment. J. Environ. Sci. Health. PartA, 13, 687-695, 1978.

Miller, J. M., A five-year climatology of five-day back trajectories from Barrow, Alaska, Atmos, Environ, 15, 1401-1405, 1981a.

Miller, J. M., A five-year climatology of back trajectories from Mauna Loa Observatory, Hawaii, Atmos. Environ., 15, 1553-1558, $1981 \mathrm{~b}$.

Miller, J. M., and J. M. Harris, The flow climatology to Bermuda and its implications for long-range transport, Atmos. Environ., 19. 409-414, 1985.

Miller, J. M., J. N. Galloway, and G. E. Likens, Origin of air masses producing acid precipitation at Ithaca, New York - A preliminary report, Geophys. Res. Lett., 5, 757-760, 1978.

Morales, C., Saharan Dust, SCOPE 14, 310 pp., John Wiley, New York, 1979.

Nriagu, J. O., Global inventory of natural and anthropogenic emissions of trace metals to the atmosphere, Nature, 279, 409-411, 1979.

Pacyna, J. M., Trace element emission from anthropogenic sources in Europe, Tech. Rep. NILU 10/82, Ref. 24781, 107 pp., Norw. Inst. for Air Res., Lillestrom, 1983.

Pacyna, J. M., Estimations of the atmospheric emissions of trace elements from anthropogenic sources in Europe, Atmos. Environ. 18, 41-50, 1984.

Pacyna, J. M., Spatial distributions of the $\mathrm{As}, \mathrm{Cd}, \mathrm{Cu}, \mathrm{Pb}, \mathrm{V}$ and $\mathrm{Zn}$ emissions in Europe within a $1.5^{\circ}$ Grid net, Tech. Ren. NILU OR60/85, Ref, 0-8551, Norw. Inst. for Air Res., Lillestrom, 1985.

Pacyna, J. M., A. Semb, and J. E. Hanssen, Emission and long-range transport of trace elements in Europe, Tellus. 36B, 163-178, 1984.

Parungo, F., J. Harris, B. Rosenwasser, and L. Ruhnke, Analyses of aerosol and precipitation samples collected during a transatlantic research cruise, NOAA Tech.Memo, ERL ESG-5, 63 pp., Natl. Oceanic and Atmos. Admin., Boulder, Colo., 1984.

Peirson, D. H., P. A. Cawse, and R.S. Cambray, Chemical uniformity of airborne particulate material, and a maritime effect, Nature, 251 . 675-679, 1974.

Piotrowicz, S. R., B. J. Ray, G. L. Hoffman, and R. A. Duce, Trace metal enrichment in the sea surface microlayer, L. Geophys. Res. 77. 5243-5254, 1972.

Polian, G., and G. Lambert, Radon daughters and sulfur output from Erebus volcano, Antartica, J_Yolcanol.Geotherm. Res., 6 . 125-137, 1979.

Prodi, F., and G. Fea, Transport and deposition of Saharan dust over the Alps, Proc.Int. Congr. Meteorol, 15th, 1, 179-182, 1978.

Prospero, J. M., Mineral and sea salt aerosol concentrations in various ocean regions, J. Geophys. Res, 84, 725-731, 1979.

Quinby-Hunt, M. S., and K. K. Turekian, Distribution of elements in sea-water, Eos. Trans AGU, 64, 130-131, 1983. 
Rahn, K. A., The chemical composition of the atmospheric aerosol Tech. Red, 275 pp., Univ. of R. I., Kingston, 1976.

Rahn, K. A., The $\mathrm{Mn} / \mathrm{V}$ ratio as a tracer of large-scale sources of pollution aerosol for the Arctic, Atmos. Environ, 15, 1457-1464, 1981.

Rahn, K. A., and D. H. Lowenthal, Elemental tracers of distant regional pollution aerosols, Science, 223, 132-139, 1984.

Reiter, E. R., Handbook for forecasters in the Mediterranean; Weather Phenomena of the Mediterranean basin, Rep. 1, General description of the meteorological processes, Tech. Rep. ENVPREDRSCHFAC 5-75, 344 pp., Environ. Predict. Res. Facil., Monterey, Calif., 1975.

Seghaier, A., Abondance et origine de quelques métaux ( $\mathrm{Al}, \mathrm{Fe}, \mathrm{Zn}, \mathrm{Cu}$, $\mathrm{Cd}, \mathrm{Pb}$ ) dans l'aérosol marin de la Méditerranée occidentale, Thèse $3 \mathrm{e}$ cycle, Univ. of Paris 7, 1984.

Settle, D. M., and C. C. Patterson, Magnitudes and sources of precipitation and dry deposition fluxes of natural and industrial leads to the North Pacific at Enewetak, L. Geophys. Res., 87, 8857-8869, 1982.

Sykes, R., and L. Hatton, Computation of horizontal trajectories based on the surface geostrophic wind, Atmos. Environ. 10, 925-934, 1976.

Taylor, S. R., Abundance of chemical elements in the continental crust: A new table, Geochim. Cosmochim. Acta, 28, 1273-1285, 1964.

Thurston, G. D., N. M. Laird, K. A. Rahn, and D. H. Lowenthal, Comments and Response on Elemental tracers of distant regional pollution aerosols, Science, 227 pp. 1406, 1408, 1412, 1985.

Tomadin, L., R. Lenaz, V. Landuzzi, A. Mazzucotelli, and R. Vanucci, On wind-blown dusts over the Central Mediterranean, Oceanol, Acta, 7, 13-23, 1984.

Turekian, K. K., Geochemical distribution of elements, in McGraw-Hill Encyclopaedia of Science and Technology vol.4, pp. 627-630, 1971.

Van der Waerden, B. L., Statistique Mathématique, 371 pp., Dunod, Paris, 1967.

Viala, A., F. Gouezo, B. Mallet, J. Fondarai, J. P. Cano, J. M. Sauve, F. Grimaldi, and E.Deturmeny, Mesure de quatre metaux-traces
(Plomb, Cadmium, Chrome et Zinc) dans les poussières atmosphériques à Marseille de 1977 à 1979, Pollut. Atmos., 21, 207-222,1981.

Vinogradov, A. P., The Geochemistry of Rare and Dispersed Chemical Elements in Soils, 2nd ed., Consultants Bureau Inc., New York, 1959

Walsh, P. R., K. A. Rahn, and R. A. Duce, Erroneous elemental mass-size functions from a high volume cascade impactor, Atmos. Environ., 12, 1793-1795, 1978.

Wedepohl, K. H., Geochemistry, Holt, Reinhart and Winston, New York, 1971.

Weisel, C. P., Cadmium and lead enrichments on sea salt aerosols above Narrangasett Bay collected by the bubble interfacial microlayer sampler, M.S. Thesis, Univ. of R. I., Kingston, 1978.

Weisel, C. P., The atmospheric flux of elements from the ocean, Ph. D. Thesis, Univ. of R. I., Kingston, 1981.

Weisel, C. P., R. A. Duce, J. L. Fashing, and R. W. Heaton, Estimates of the transport of trace metals from the ocean to the atmosphere, $\mathrm{L}$ Geophys. Res., 89, 11607-11618, 1984.

Woodcock, A. H., Salt nuclei in marine air as a function of altitude and wind force, J, Meteorol., 10, 362-371, 1953.

Zoller, W. H., E. S. Gladney, and R. A. Duce, Atmospheric concentrations and sources of trace metals at south pole, Science, $183,198-200,1974$.

M. Arnold, P. Buat-Ménard, F. Dulac, and U. Ezat, Centre des Faibles Radioactivités, Laboratoire Mixte Centre National de la Recherche Scientifique/ Commissariat à l'Energie Atomique, Domaine du CNRS, B.P. No.1, 91190 Gif-sur-Yvette, France.

D. Martin, Centre de Recherches en Physique de l'Atmosphère, Etablissement d'Etudes et de Recherches Météorologiques, 78470 Magny-Ies-Hameaux, France.

(Received July 14, 1986; revised January 20,1987 ; accepted January 23, 1987.) 